San Jose State University

SJSU ScholarWorks

Master's Theses

Master's Theses and Graduate Research

1989

\title{
Toward a grounded theory of innovation communication in the collateral organization
}

Signe Larson Larkin

San Jose State University

Follow this and additional works at: https://scholarworks.sjsu.edu/etd_theses

\section{Recommended Citation}

Larkin, Signe Larson, "Toward a grounded theory of innovation communication in the collateral organization" (1989). Master's Theses. 3153.

DOI: https://doi.org/10.31979/etd.vbw2-mprf

https://scholarworks.sjsu.edu/etd_theses/3153

This Thesis is brought to you for free and open access by the Master's Theses and Graduate Research at SJSU ScholarWorks. It has been accepted for inclusion in Master's Theses by an authorized administrator of SJSU ScholarWorks. For more information, please contact scholarworks@sjsu.edu. 


\section{INFORMATION TO USERS}

The most advanced technology has been used to photograph and reproduce this manuscript from the microfilm master. UMI films the text directly from the original or copy submitted. Thus, some thesis and dissertation copies are in typewriter face, while others may be from any type of computer printer.

The quality of this reproduction is dependent upon the quality of the copy submitted. Broken or indistinct print, colored or poor quality illustrations and photographs, print bleedthrough, substandard margins, and improper alignment can adversely affect reproduction.

In the unlikely event that the author did not send UMI a complete manuscript and there are missing pages, these will be noted. Also, if unauthorized copyright material had to be removed, a note will indicate the deletion.

Oversize materials (e.g., maps, drawings, charts) are reproduced by sectioning the original, beginning at the upper left-hand corner and continuing from left to right in equal sections with small overlaps. Each original is also photographed in one exposure and is included in reduced form at the back of the book. These are also available as one exposure on a standard $35 \mathrm{~mm}$ slide or as a $17^{\prime \prime} \times 23^{\prime \prime}$ black and white photographic print for an additional charge.

Photographs included in the original manuscript have been reproduced xerographically in this copy. Higher quality 6 " $\times 9$ " black and white photographic prints are available for any photographs or illustrations appearing in this copy for an additional charge. Contact UMI directly to order.

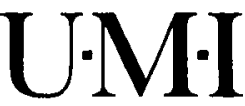

University Microfilms International

A Bell \& Howell Information Company

300 North Zeeb Road, Ann Arbor, MI 48106-1346 USA

$313 / 761-4700 \quad 800 / 521-0600$ 
$[-\cdots-\ldots+\ldots$ 
Order Number 1388706

Toward a grounded theory of innovation communication in the collateral organization

Larkin, Signe Larson, M.A.

San Jose State University, 1989

Copyright @1989 by Larkin, Sigme Larson. All rights regerved.

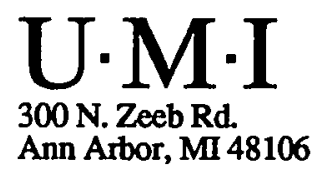


TOWARD A GROUNDED THEORY OF INNOVATION COMMUNICATION

IN THE COLLATERAL ORGANIZATION

\author{
A Thesis \\ Presented to \\ The Faculty of the Communication studies Department \\ San Jose State University
}

In Partial Fulfillment

of the Requirements for the Degree

Master of Arts

By

Signe Larson Larkin

August, 1989 
APPROVED FOR THE COMMUNICATION STUDIES DEPARTMENT
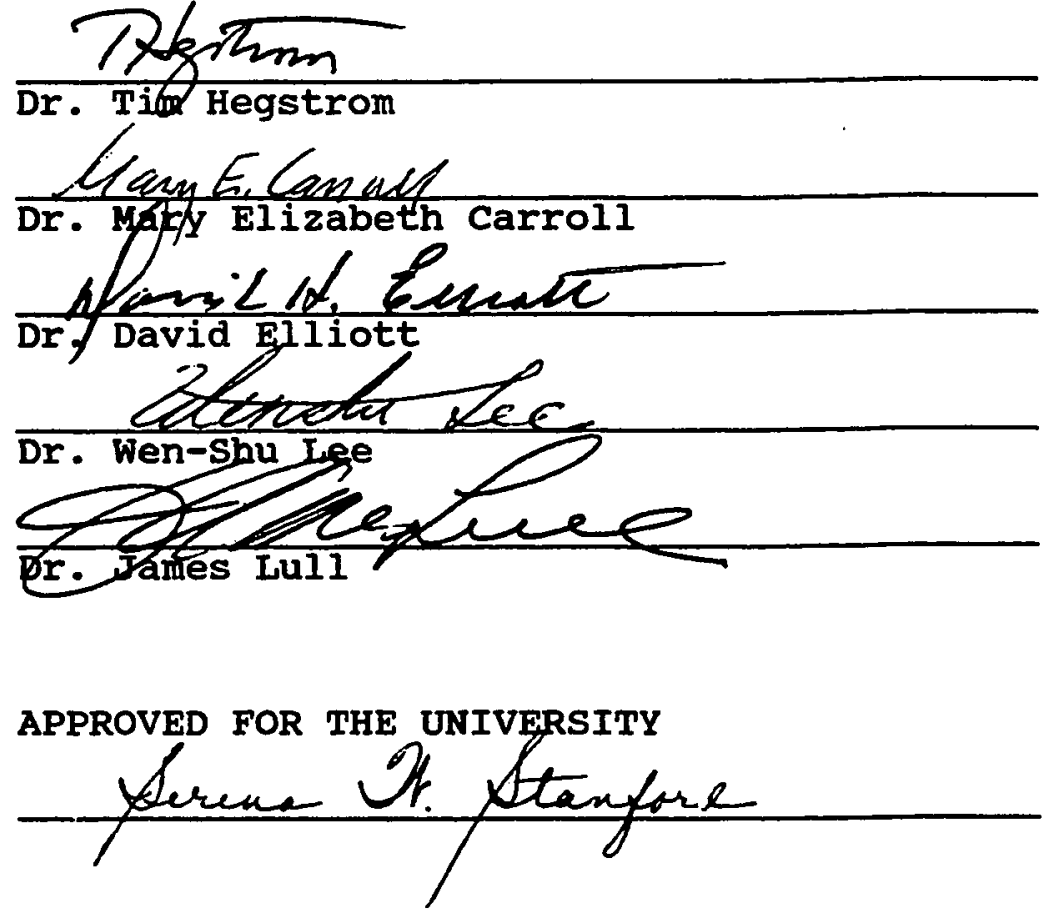
Copyright Signe Larson Larkin, 1989 
ACKNOWLEDGEMENTS

A professor in this department has described my year-long quest toward an M.A. as a process wherein I have taken a 2 by 4 and knocked down doors. While I appreciate the humor of this metaphor, it is not true. For, many doors have been opened for me by individuals whom I am privileged to acknowledge.

My thesis adviser, Tim Hegstrom, has earned my great respect and admiration. He not only made this thesis possible, he must take credit for any aspects of it that are well-done. I thank him for all the time, effort, and caring that he expended on my behalf. He held the door open for me the whole time.

The committee members were also a great source of support and guidance. David Elliott, another door opener, has shown unfailing grace and commitment to enhancing the quality of both my work and my self. Wen-Shu Lee has been both rigorous and compassionate, for which I am grateful. Betsy Carroll, my first seminar professor, I count as a friend and mentor. James Lull graciously consented to take on the burden of my thesis, and in so doing, has provided the guidance and direction that this study has taken. My thesis committee has truly been, both individually and collectively, generous and supportive. 
My unofficial thesis committee deserves mention for the large part it played in the whole process:

Phil Wander, who always had a clean handkerchief: My great officemates, Cecilia Regan, Kris Adams, Kanda Whaley, Pamela Oleson, and Susan Taylor, who always had advice, commentary, and insight for me;

My Comm 20 students, who heard a blow-by-blow description of "The Saga of the Thesis," and always showed an interest and caring.

I thank them all.

In the spirit of "the first shall be last," I must acknowledge my exceptional family for their warm acceptance and unfailing support. My children, Caitlin, Devin, Ian, Gavin, Jade, Morgan, and Jordan, were each uniquely helpful. (Yes, guys, eventually you may call me Mama Doc!) Finally, I dedicate this thesis to the two people in my life who have had the most impact on my education: my late father, Rolf Larson, and my husband, Greg Larkin. My father taught me to love the poetry of learning, and my husband has taught me how to put this lesson into practice. I thank them each for their valuable example. 
TABLE OF CONTENTS

Chapter

Page

I INTRODUCTION . . . . . . . . . . . . 1

SPECIFIC STUDY PARAMETERS . . . . . . . 9

Phenomenological Communicative Context. . 9

Qualitative Methodology . . . . . . 10

Generating Grounded Theory. . . . . . 13

The Innovation-Decision Process . . . 15

The Collateral Organization . . . . . 18

REVIEW OF LITERATURE . . . . . . . . . 22

Generating Grounded Theory. . . . . . 22

Diffusion of Innovations . . . . . . 24

The Collateral Organization . . . . . 25

Communication in organizations . . . . 31

Account Analysis . . . . . . . . 35

BACKGROUND TO PARTICIPANT OBSERVATION • • 36

SPECIFIC SETTING FOR THIS STUDY • • • • 39

How Defense Contractors Do Business

With the Government . . . . . . 39

II METHODOLOGY . . . . . . . . . . . 47

FIELD STUDY . . . . . . . . . . . . . 47

Grounded Theory . . . . . . . . . 49

The Setting for this Research . . . . 51

vi 


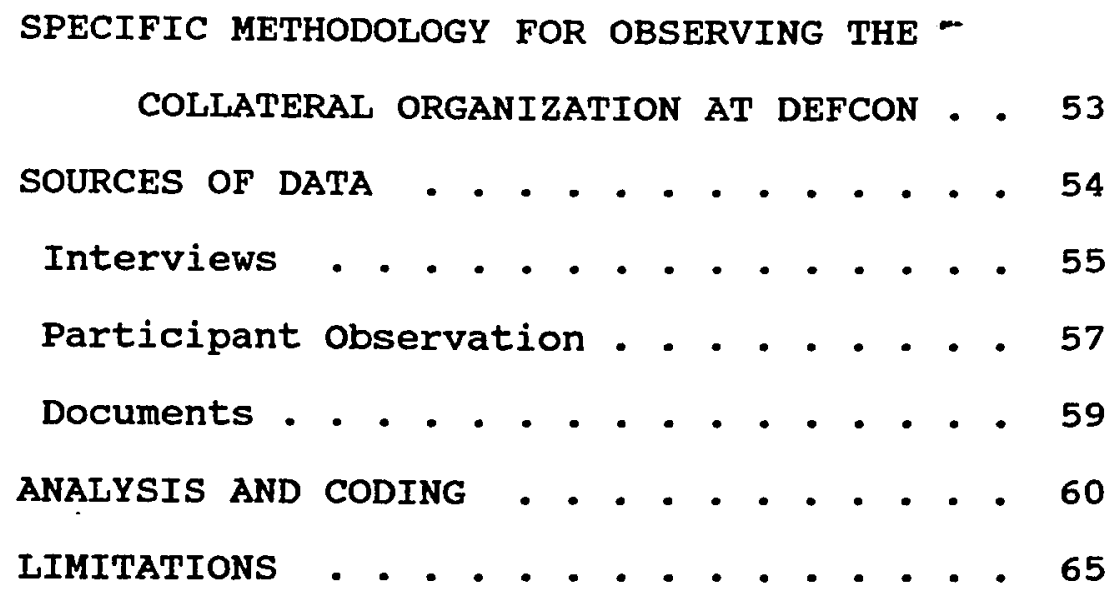

III THEORETICAL PROPOSITIONS CONCERNING

INNOVATION COMMUNICATION IN THE

COLLATERAL ORGANIZATION . . . . . . 67

THE CREATION OF SHARED REALITY • . . . . 67

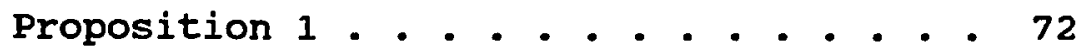

Proposition 2............ . 74

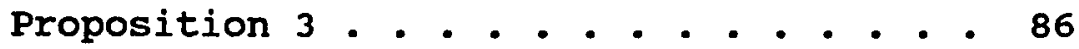

Proposition 4 . . . . . . . . . . 93

Proposition 5. . . . . . . . . . 100

Proposition 6. . . . . . . . . . 110

Proposition 7 . . . . . . . . . 129

Proposition 8 . . . . . . . . . . . 143

Proposition 9.......... . . 150

vii 
IV LET A HUNDRED FLOWERS BLOOM:

IMPLICATIONS FOR INNOVATION RESEARCH . 158

Opportunistic Innovations . . . . . 165

Selective Disclosure . . . . . . 168

Formal vs. Informal structures . . . 170

Shared Reality . . . . . . . . . 172

The Future of Innovation Research . . . 173

REFERENCES •. . . . . . . . . . . . . 178 


\begin{abstract}
TOWARD A GROUNDED THEORY OF INNOVATION COMMUNICATION

IN THE COLLATERAL ORGANIZATION

by Signe Larson Larkin

This thesis generates grounded theory in the form of nine propositions on innovation communication in the collateral organization. The data were gathered over a six-month period at a silicon Valley defense contractor. The study characterizes innovation communication and analyzes its uses in diffusing innovations at the chosen location.

Innovation communication in the collateral organization under study was divided into three categories. While the organization was searching for identity and legitimacy, innovation communication was highly rational and tentative. After the initial innovation was rejected, innovation communication became affective and emotional to release tension and establish group cohesion. Once the collateral organization was successful, innovation communication became celebratory, using metaphoric language to motivate the larger organization to accept further innovations. In this study, successful innovation communication required an accurate assessment of the situation, a willingness to start small and grow incrementally, and the development of a unique version of shared reality.
\end{abstract}


CHAPTER I

INTRODUCTION

One bit of folk wisdom tells us that "the more things change, the more they stay the same." It seems that some change is always happening, even if it is not quite the one that is wanted. similarly, while many people can recognize that a change is happening, most people are not very effective at recognizing whether or not it is a good change. For instance, consider the following misevaluated changes, as cited in a recent newspaper article (Collins, 1988, p. 1):

1. "Drill for oil? You mean drill into the ground to try and find oil? You're crazy." Drillers whom Edwin L. Drake tried to enlist to his project to drill for oil in 1859 .

2. "This 'telephone' has too many shortcomings to be seriously considered as a means of communication." Western Union internal memo, 1876. 3. "Heavier-than-air flying machines are impossible." Lord Kelvin, president, Royal Society, 1895.

4. "We don't like their sound, and guitar music is on the way out." Decca Recording Co. rejecting the Beatles.

Even though change has always taken place, in our 
modern world the pace of change has definitely increased. For instance, historians frequently note that the vast majority of inventions and other scientific advances have taken place in the twentieth century. But the changes we are seeing in the late twentieth century go far beyond the mere addition of things into our man-made environment. The changes we are seeing now involve major restructurings in the very ways we think and the ways our society itself is organized. Thus, today is a time especially ripe for change, even in our fast changing world: "We are living in one of those rare times in history when the two crucial elements for social change are present--new values and economic necessity" (Naisbitt and Aburdene, 1985, p. 2).

Nowhere are these forces for change felt more strongly than in the organizational workplace. This is because the very nature of the work being done is changing, and with it, the economic underpinnings of our society are also changing. One of the most frequently cited examples of this sort of underlying change is that organizations are switching from a product orientation to an information orientation. In the past twenty years, the majority of workers have switched from handling things to handling information 
(Harris, 1983, p. 3). This change has profound implications for society as a whole and for all the organizations within it.

One of the most profound implications is that in the new information centered organization, the focus is on communication, not on some physical product. The new organizations produce information, not physical products, and the information product as well as its delivery system is communication, which therefore becomes central to the organization itself. As Katz and Kahn (1978) indicate, "Communication--the exchange of information and the transmission of meaning--is the very essence of a social system or an organization" ( $p$. 428). Today's organization cannot be separated from the communication which is at once its internal lifeblood, its external product, and its interface with the world.

Communication is equally central to the process of change itself. Our organizations and the changes we are seeing in them are both communication centered and made manifest to us through communication. For an ever increasing number of us, the work we do is communication and the organizations in which we do it are communication "factories." Thus, it behooves us to know all we can about how communication and change are 
incerrelated, on both organizational and personal levels.

Four major factors influence the change process: (a) the nature of the change itself, (b) the social system in which the change takes place, (c) the time required for the change to occur, and (d) the communication through which the change is effected. Communication is the least studied of these four. factors (Cheney, Block, and Gordon, 1986, p. 214). Much of the work done to date on change and communication is at a fairly abstract level. Thus, we have yet to see empirical studies that get to the level of examining concrete organizations in detail, because the theoretical work is just getting fully in place to support such studies. As Pettigrew (1987) says, "Much research on organizational change is ahistorical, aprocessual, and acontextual in nature - - There are remarkably few studies of change that actually allow the change process to reveal itself in any kind of substantially temporal or contextual manner" (p. 655). These shortcomings have led one recent researcher to conclude, "It is now a widely accepted view that we need to develop concepts for the evaluation of change" (Carnall, 1986, p. 745). What is needed are more and better studies designed to reveal 
the interrelationships among the history, processes, and contexts of change.

As we begin to study organizations, change, and communication simultaneously, it is evident that we must first of all develop ways of looking at organizations that fit their dynamic nature. The organizational phenomena communication researchers face are described by Etzioni (1975):

The study of communication in organizations is of special import because the large size, high degree of complexity, strain toward effectiveness, and elaborate control structure of organizations all require extensive communication networks and roles and mechanisms especially devoted to the flow of communication. (p. 241)

We need to look at organizations in ways that stress not their fixed structures, but their dynamic interactions both with their environment and within themselves. One such useful new way to examine organizations is the interpretive view, as opposed to the traditional or functionalist view. These two perspectives are contrasted at length by Putnam (1983). The essential distinction between the two views is that from the traditional view the organization is static, whereas from the interpretive view it is dynamic: "The 
Functionalist (traditional) view looks upon the organization as a concrete entity with 'real world' existence . . . The Interpretive view suggests that the social world does not have an objective, independent existence which imposes itself upon human beings" (Faules, 1982, p. 151). This interpretive view encourages the researcher to examine the organization from the inșide, as the participants themselves see it. We must also develop new ways of looking at change, especially in organizational settings. The research on change is profuse and diffuse. One useful way to restrict our study to a meaningful subset of all changes is to examine only new changes, as opposed to those changes which employ ideas or approaches that are already well known. New changes are referred to as innovations and the process by which they are spread in an organization is called diffusion (Rogers, 1983, pp. 5-6). Clearly, communication is required any time a new idea is spread within an organization. Thus, "Diffusion is a subset of communication research that is concerned with new ideas" (Kelly and Kranzberg, 1978, p. 277).

Diffusion of innovations is the systematic analysis of how ideas are started and spread in a social system, i.e., an organization itself, as well as between and 
among organizations. What we especially need for this sort of analysis is research that shows the interrelationships among organizations, communication, and change. Every proposed innovation must be communicated to organizational decision makers, who must in turn communicate their decision back to the proposers of the change. But this process has not been effectively studied: "We lack an understanding of how communication and decision-making processes are involved in innovation within organizations," say Kelly and Kranzberg (1978, p. 275).

The specific analysis that needs to be made centers on the communicative acts of innovators and decision makers in a specific organization. As Kelly and Kranzberg (1978) have suggested, this study examined the communication through which innovations are spread in an organization, with special emphasis on how communication between innovators and decision makers affects the diffusion of the innovations. These communications have been termed innovation communication, which is defined as ". . all oral and written messages concerning an innovation that are sent and received anytime from the point of inception to the point at which the innovation is eventually adopted, rejected, or simply forgotten" (Cheney, Block, and 
Gordon, 1986, p. 214). By analyzing this innovation communication, this study will reveal how individual communicators and their particular communications dynamically interact with the diffusion of innovation.

To accomplish research on innovation communication, the full process of the diffusion of innovation must be examined from as rich a variety of viewpoints as possible. In particular, as Cheney, Block, and Gordon (1986) point out, to provide an understanding of history, process, and context, both oral and written messages about each innovation must be studied starting before the formal decision process is even underway ( $p$. 214). Such a depth and breadth of data help to overcome the limitations of prior research. A more fruitful approach to research in innovation communication, as enumerated by Cheney, Block, and Gordon (1986, p. 215), includes the following:

1. broadening the conceived role of communication to include messages that serve an early discussion function, i.e., those that do not pertain to the actual diffusion of an innovation; and then

2. examining all communication relevant to the process of innovation in organizations, which includes messages from the early stages of the diffusion process. 
SPECIFIC STUDY PARAMETERS

Phenomenological Communicative Context

A major philosophy underlying the interpretive view of organizations is phenomenology. In the traditional view of organizations, reality lies somewhere outside of the individual. In this view, the members of an organization encounter the organizational context as something outside of themselves. However, in the phenomenological view, although reality may have existence outside of the individual, the meaning of that reality is determined by individual interpretive processes. The philosophical roots of this view of the dynamic relationship between reality and meaning lie in the study of phenomenology, a European philosophy developed by Brentano and Husserl. Phenomenology has been called "a broad stream with many currents" (Sanders, 1982, p. 354). This study does not attempt to discuss phenomenology in all its streams and currents; however, those streams and currents are described in general and their relationships to organizational research are defined by Sanders (1982). This study examined organizational communication from a phenomenological point of view, by studying innovation communication from the individual communicator's point of view. The focus was on the communicative 
interaction between the individual and the overall

process of innovation.

This phenomenological view of reality has important implications for organizational communication and research. First of all, this stance implies "a view of man as an active, self-directing, self-monitoring agent whose acts occur in a social framework constituted out of meanings" (Harré and secord, 1973, p. 297). These meanings are the creation of the individual member of the organization and are a legitimate field of study for the researcher. As Deetz says, "Interpretive research is thus to analyze organizational reality-what is presumed as real--as well as its social reality--consensually shared subjective interpretations" (Deetz, 1982, p. 134). The ability to see the organization as its members see it is essential to achieving the goals of this study and determines the appropriate methods to be used in data gathering.

\section{Qualitative Methodology}

Since we are interested in the interrelationship between the process of innovation and the individuals within it, this study examined the organization from the individual's point of view. This participantcentered view is what distinguishes qualitative 
research methodologies from other approaches:

The phenomenologist is concerned with understanding human behavior from the actor's own frame of reference ... The phenomenologist . . . seeks understanding through such qualitative methods as participant observation, open-ended interviewing, and personal documents. These methods yield descriptive data which enable the phenomenologist to to see the world as subjects see it. (Bogdan and Taylor, 1975, p. 2)

Another advantage that qualitative methods offer is that at least indirectly they provide a contextual view of the subject under study, which is ". . not reduced to an isolated variable or to an hypothesis, but is viewed instead as part of a whole" (Bogdan and Taylor, 1975, p. 4). The richness of the holistic viewpoint is essential to an accurate understanding of the role played by innovation communication in the total process by which an innovation is diffused. Qualitative methods allow the researcher to take a participant-centered view; they are "a way to move beyond the simple description of relational structures to an interpretation of them . . . The process of research is an effort to justify the perceived nature of social structuring from the researcher's and the 
respondents' vantage points" (Albrecht and Ropp, 1982, pp. 162-163)

The essential attributes of effective qualitative research are significant participant observation by the researcher and the arrangement of these observations into terms and categories matching the perceptions of those involved:

In order to build a plausible interpretation of how organizational members communicatively make sense of their interlocked actions, it is necessary to have recourse to the body of knowledge that members draw upon to make sense. What is required then are details--detailed observations of organizational members "in action" and detailed interviews (formal or informal) of organizational members accounting for their actions. . . What we envision as sufficient procedures for gathering organizational culture data require the researcher to . . become intimately familiar with the organizational life he or she is interpreting, so that the organizational experiences are understood in terms of the understandings of organizational members. (Pacanowsky and O'Donnell-Trujillo, 1982, p. 127) The qualitative approach to research described above implies the generation of data from an involved, 
descriptive, and inductive point of view. This allows the researcher to approximate the reality of the organizational "natives."

\section{Generating Grounded Theory}

A specific methodology which is both qualitative and interpretive in nature has been developed by Glaser and Strauss (1967). Indeed, it is consistent with a phenomenological viewpoint, for as Putnam (1982) tells us, "Glaser and Strauss' grounded-theory methodology, though not specifically designed for the interpretive school, can be combined with notions of intersubjectivity, enacted sense-making, or social construction of reality to conduct research within this paradigm" (p. 202).

In carrying out academic research, one proceeds from theory to data, or from data to theory. Proceeding from data to theory presents at least two alternatives: the logico-deductive theory which tests logical deductions borne from a priori assumptions, or the development of theory from analytical research data (Fisher and Hawes, 1971, p. 444).

Glaser and Strauss (1967) emphasize the notion that generating theory from the analysis of research data offers several advantages, especially in a study that 
is longitudinal, and generated by participant observation:

1. grounded theory can prevent forcing data into theories which have a dubious fit;

2. grounded theory can be useful for generating theory in areas that are "new";

3. grounded theory can be used to study social units of any size (pp. 1-28).

In generating grounded theory, one of the methods used is the constant comparative method. This method involves, just as the term implies, a constant checking and re-checking of the data, comparing, and analyzing to generate categories and properties within the data. These categories and properties are used as an empirical ground for the emerging theory. Glaser and Strauss explain categories and properties and their relations to theory thus: "Making a distinction between category and property indicates a systematic relationship between these two elements of theory. A category stands by itself as a conceptual element of the theory. A property, in turn, is a conceptual aspect or element of a category" (p. 36).

The grounded theory method assumes that categories will be revised through time and further analysis, but without diluting or destroying the properties. It is 
emphasized that "conceptual categories and properties have a life apart from the evidence that gave rise to them" (p. 36). That is, the data exist objectively, and apart from the researcher's interpretation of them.

The Innovation-Decision Process

The events examined in this study are diffusions of innovations, which are parts of a process that takes place over time. This process must be well understood, so that no relevant data are ignored.

Kanter (1988) has summarized four distinctive characteristics of innovation:

1. The innovation process is uncertain.

2. The innovation process is knowledge-intensive.

3. The innovation process is controversial.

4. The innovation process crosses boundaries. (pp. 170-171)

Kanter (1988) warns against "the usual process models of innovation that posit discrete stages through which an innovation idea progresses," and adds "that stage models do not always adequately capture the giveand-take of innovation, and they risk artificially segmenting the process" (p. 172).

Kanter's model consists of four stages: (1) Idea Generation and Innovation Activation, (2) Coalition 
Building, (3) Idea Realization and Innovation Production, and (4) Transfer and Diffusion. Her discussion of each of these stages makes it clear that she does not view them as mutually exclusive. This makes her model more flexible than most others, but also harder to use, since any given data could easily fit in any of her stages as she defines and explicates them. Kanter's flexible model is thus more descriptive of a theory than it is useful as a tool for interpreting large volumes of field-generated data. The best known model for the innovation-decision process is provided by Rogers (1983, p. 165). Rogers provides the following definitions of the five stages of the process:

1. Knowledge occurs when an individual (or other decision-making unit) is exposed to the innovation's existence and gains some understanding of how it functions.

2. Persuasion occurs when an individual (or other decision-making unit) forms a favorable or unfavorable attitude toward the innovation. 3. Decision occurs when an individual (or other decision-making unit) engages in activities that lead to a choice to adopt or reject the innovation. 4. Implementation occurs when an individual (or 
other decision-making unit) puts an innovation into use.

5. Confirmation occurs when an individual (or other decision-making unit) seeks reinforcement of an innovation-decision already made, but he or she may reverse this previous decision if exposed to conflicting messages about the innovation. (p. 164) This model is useful for anyone studying the process by which an innovation is diffused; however, the stages are simultaneously macro-level and confining. This study was undertaken at a micro-level (i.e., it examined individual messages in one collateral organization), thus making the macro-level view less useful. Also, since this study examined six innovations taking place at one company in a short period of time, there was considerable overlap among the six. As a result, Rogers' rigidly defined five stages were also constantly overlapping. For instance, when the first successful innovation was implemented, most of the first stages of Rogers' model were bypassed completely in successive innovations. In fact, a linear process with recognizable stages was almost impossible to detect for most of the innovations generated in the organization studied by this author. More importantly, this bypassing of stages had 
significant impacts on the communication in the collateral organization, as will be shown in the findings chapter.

The Collateral Organization

As the wide variety of models for the innovationdecision process indicates, innovation can be viewed from many perspectives. Furthermore, even one model, such as Kanter's or Rogers', consists of many subparts and permutations. What is needed to support actual field work is some meaningful subset of the possible angles from which innovation can be viewed. This study used the collateral organization as such a limited frame of reference from which to analyze accounts of innovation communication.

The collateral organization is a term coined by Zand (1981) and defined as ". . a parallel, coexisting organization which a manager can use to supplement the existing formal organization" (p. 58). Zand adds further details to the definition:

A collateral organization has different norms--that is, standards of behavior, methods of making decisions, and procedures--than those in the formal organization. The different norms are deliberately designed to make the collateral organization more 
suitable for identifying and solving problems which seem intractable in the formal organization. No new people are required and the collateral organization is carefully linked to the "regular" organization. (p. 58)

Zand (1981) lists the following characteristics of the collateral organization:

1. All communication channels are open and connected.

2. Relevant communication is rapid and complete.

3. Normal organizational goals, assumptions, methods, alternatives, and criteria for evaluation are all open to careful questioning and analysis. 4. The manager using the collateral organization can invite participation from those outside his or her normal range of control. (pp. 67-68)

Zand (1981) also provides the following distinctions between the collateral organization and the formal existing organization (which stays in place while the collateral organization is functioning):

1. The collateral organization's job is to identify and solve problems not solved by the formal organization.

2. The collateral organization creatively complements the formal organization with new combinations of 
people, new channels of communication, and new ways of seeing old problems.

3. The collateral organization operates in parallel with the formal organization; it does not displace the formal organization.

4. The collateral organization does not hire any new people from outside the organization.

5. The output of the collateral organization is used as input to the formal organization.

6. To facilitate new ideas and new approaches, the collateral organization uses different norms from those of the formal organization. (p. 67) Collateral organizations have been around for centuries, but they have been formally studied for less than a decade. Their temporary nature has tended to keep them from the same level of formal scrutiny as more permanent organizational phenomena have received. But although temporary, the collateral organization often plays a pivotal role in organizational life, because its very nature is such that it only appears in times of crisis, problem, or change. Furthermore, the collateral organization is one of the few formal structures in which individuals from various levels throughout the company are brought together for a common purpose. Therefore, the collateral organization 
is a promising location from which to examine the communicative landscape to see if any unusual communicative behaviors regularly take place there. This study was a specific response to a general call for further research delivered by Cheney, Block, and Gordon (1986):

Future work should seek to analyze separately and together the two major functions of "innovation communication"--the early discussion function and the actual diffusion-adoption of innovations. And, the richness of terminology for and about new ideas should be further exploited by more in-depth qualitative investigations, for example, in analyses of how organizational members talk about change. (Cheney, Block, and Gordon, 1986, p. 228)

Because the communication of a collateral organization has not been studied before, and because a theory of innovation communication has not been formulated, generating theory from a longitudinal study of a successful innovation process should be undertaken as a basis for an empirically-based set of propositions on innovation communication. The purpose of this study is to generate such empirically-grounded propositions on innovation communication in a collateral organization. 
REVIEW OF LITERATURE

Generating Grounded Theory

Dubin (1976), in explaining the conceptual

foundations of theory building, states: "Observation

and description of the real world are the essential

points of origin for theories" (p. 18). He then

explains the sequence that building and generating

theory requires as being inductive and processual.

He defines a theory as "an attempt of man to model some aspect of the empirical world" (p. 26). Dubin states that a theorist is simply trying to make sense of the real world, by ordering and simplifying it

conceptually. However, a systematic and precise method is needed by the theory builder to generate theory which is based on her observation and description of the external world.

Utilizing the concepts of Glaser and Strauss (1967) in generating grounded theory, researchers have been able to develop typologies, categories, and theoretical frameworks for diverse organizational phenomena. Notable works in the area of organizational communication which have employed this methodology include Fisher and Hawes (1971), who generated theory of small groups from a systems perspective; Husband (1985), who developed a typology of organizational 
leadership behavior; Henderson (1981), who generated theory on reality bargaining; and Whitfill (1981), who studied loosely coupled systems with a grounded theory methodology.

Each of these researchers sought to overcome confusion or perceived inaccuracies in the literature by "allowing" the data to generate new theory. Fisher and Hawes for instance, argue that theory development for small groups was necessary because of the lack of a broad, shared frame of reference in small group study. Homans (1950) concurs with this assessment of the lack of broad, generalized framework in small group work: "We have pursued the higher branches of our science before the trunk was strong. We have not grown because we have had nothing to grow from" (p. 5).

Generating grounded theory is a useful methodology when researchers, like Fisher and Hawes, feel that a solid foundation of empirical work is still lacking, and yet theorizing is taking place at several levels above this incomplete foundation, or in Homans' words, in "higher branches before the trunk was strong." Generating grounded theory is also a useful methodology when differentiation and integration among existing conceptual distinctions are lacking. Husband (1985) gathered data on leadership behavior which he 
anticipated would lay groundwork to differentiate and integrate leadership styles and behavior patterns.

Finally, employing Glaser and strauss' methodology in pilot studies is especially useful, because it can give the researcher a preliminary conceptualization of what the data are going to be speaking to, if anything. Diffusion of Innovations

The specific communication activity which this study examined is diffusion of innovations. simply put, an innovation is "any idea, practice, or material artifact perceived to be new by the relevant unit of adoption" (Zaltman, Duncan, and Holbek, 1973, p. 158). An innovation differs from a change in that a change does not have to be something new, whereas an innovation must be new. Thus, all innovations imply change, but not all changes imply innovation.

Diffusion refers to the method of communicating an innovation. Specifically, "Diffusion is the process by which an innovation is communicated through certain channels over time among the members of a social system. It is a special type of communication, in that the messages are concerned with new ideas" (Rogers, 1983, p. 5)

In analyzing diffusion of innovations, the researcher must ask three essential questions: 
1. What change is to be made?

2. Why is the change to be made?

3. How can the change be put into effect?

In other words, what model or vision guides the movement toward change? (Walton, 1987, p. 15)

Rogers (1983) offers two models of the innovation process. The first, which focuses on the sources of innovation, stresses the limited number of previous diffusion studies (p. 136). The second delineates two major phases--initiation and implementation (p. 363).

As this review indicates, the process of innovation diffusion has been examined in numerous contexts. The focus of this prior research has usualiy been the innovation itself or the organizations through which the innovation was diffused. What has been less often examined are the details of the communication process used. What has not been examined at all are the specific communication devices used within a collateral organization when it is the agent through which the innovation is diffused.

The Collateral Organization

The collateral organization was first described by Zand in an introductory article (1974), followed by a more detailed discussion in his book-length study (1981). Zand (1981) describes the collateral 
organization as a parallel and coexisting organization to the larger and preexisting organization, created to consider problems that the normal organization cannot solve (p. 58). As such, the collateral organization is a secondary mode (p. 59). Zand (1981) offers a detailed list of ways in which the collateral organization differs from the normal organization (pp. 66-68). Landen and Carlson (1982) offer strong support for the collateral organization:

As a concept, the collateral organization has unlimited application. . . Creating collateral organizations is a very powerful way of restructuring existing hierarchical organizations. (p. 317)

French and Bell (1984) are equally supportive of the collateral organization as an agent of structural change in an organization:

The collateral organization described by zand is an OD effort in microcosm. A successful effort of this kind would appear to have great promise for providing the interest and skills for a more extensive application of OD technology in the organization. (p. 208)

Finally, Stein and Kanter (1980) summarize the many advantages of "parallel" organizations over 
"bureaucratic" ones. Essentially, the parallel organization is better at problem solving and focusing the resources of the total organization. Similarly, Fisher (1981) discusses the collateral organization as a structural approach to problem solving (p. 391). The need for and uses of collateral organizations were noted before zand first introduced the term: There is a rising use of temporary task teams who meet for limited periods of time and address their activities to limited problem areas. The growing complexity of organizational and technological problems has created a strong need for collaboration and coordination of the diverse resources which can be brought to bear on relevant problems. (Margulies and Wallace, 1973, p. 99)

Aiken and Hage (1971) anticipated the collateral organization by stating: "In particular, a diversity of occupations, high involvement in professional associations, high intensity of scheduled communications, and high intensity of unscheduled communications with those of higher status, both within and between departments, are highly related to the degree of innovation" (p. 79). They also added: "Having a staff with persons with training in a variety of disciplines is one such mechanism since it brings 
about a cross-fertilization of ideas from the confrontation of different perspectives in a common problem-solving situation" (p. 80).

Finally, Utterback (1971) also anticipated the collateral organization by stating: "It appears that diversity of work assignments and environment as well as development of individuals' skills in the synthesis of diverse stimuli will encourage the generation of new ideas. - . A second method for transfer [of new technology] is the migration of personnel across boundaries" (p. 85).

In more modern terms, Pettigrew (1987) has referred to the formation of parallel organizations as "attempts to change inner context [by] creating permanent and temporary changes in administrative mechanisms and working groups" (p. 667). Connor and Lake (1988) have discussed such changes from three perspectives: using external change agents, internal change agents, or a hybrid between the two (pp. 111-113).

One of the most crucial elements of the collateral organization is its cross-disciplinary nature (Carnall, 1986, p. 745), described by Zand (1981) as "new combinations of people, new channels of communication, and new ways of seeing old ideas" (p. 67). Naisbitt and Aburdene (1985) have noted that Fortune magazine's 
eight most innovative companies are all masters of the cross-disciplinary team (p. 32). Showing the tie between cross-disciplinary teams and innovation, Zaltman, Duncan, and Holbek (1973) state: "The diversity in occupational backgrounds can then bring a variety of sources of information to bear, which can facilitate awareness or knowledge of innovations at the initiation stage" (p. 135). They go on to suggest the creation of "integrator" groups, set up to help coordinate efforts and reduce conflict among many differing groups (p. 150). Kanter (1982) summarizes the genesis of such a team: "For creative accomplishments, these power-related tools do not come through the vertical chain of command but rather from many areas of the organization" (p. 99). Kanter (1982) characterizes such teams as having "multiple reporting relationships," "a free and somewhat random flow of information," and "frequent and smooth cross-functional contact, a tradition of working in teams and sharing credit widely, and emphasis on lateral rather than vertical relationships as a source of resources, information, and support" (pp. 104-105).

Scharf (1987, p. 19) identifies the exact members of such a team, from a facetiously prescriptive management perspective: 
1 person concerned about opportunity

1 person who will operate the solution

1 person to whom the solution outputs

1 person who can synthesize others' ideas

1 senior decision maker

1 technical expert

1 junior individual, if not covered above

1 trained group facilitator

1 recording secretary (with flip chart)

Scharf then adds: "This represents a vastly more powerful team than those used in quality circles, which calls for a team made up of persons doing the same or similar work" (p. 19). Davis and Lawrence (1977) offer a detailed agenda for the meetings of such a team (pp. 110-111).

Numerous examples have been cited of successful collateral organizations. Zand (1981) cited two, the Silver City Bank (pp. 68-75) and Ajax Corporation (pp. 75-83). Walton (1987) cites the example of Oslo Work Research Institute in Norway (pp. 228-244). Freedman (1988) cites an internal ventures center at Eastman Kodak (pp. 280-292). Nurick (1985) describes the use of task forces in the development of the TVA (pp. 59-88). Finally, Landen and Carlson (1982) describe the Parallel Business Planning Organization at General 
Motors (pp. 317-323). In each of these cases, all of the elements of Zand's collateral organization can be seen in realistic situations, being used to solve specific problems in the larger organization.

As this review shows, the collateral organization has been studied in terms of its relationships with change. The collateral organization is a useful method for solving problems and implementing changes. However, in these roles, it has been studied at a macro level, but not in close detail, with specific attention devoted to communication. Furthermore, the collateral organization has never been studied before as a creator and diffuser of successful innovations.

In general, the collateral organization has not been studied as often as its potential utility warrants. This study examines the innovation communication used by a collateral organization to diffuse innovations, in order to lay the groundwork for building theory about the relationship among communication, innovation, and the collateral organization.

Communication in organizations

Most texts on organizational communication dichotomize communication as being either formal or informal. Formal communication is usually defined as 
following official paths or channels, flowing in accordance with formal network relationships. Formal communication is effected through written reports, memos, meetings, and other formal channels (Goldhaber, 1986, p. 180). Generally, formal communication follows the same lines and patterns that would be found on an organization chart. These patterns, called channels, usually occur in either upward, downward, or horizontal movements.

Informal communication, on the other hand, has been defined as that communication which deviates from traditional channels or networks, usually characterized as "the grapevine." Its channel is oral, rather than written, and it is often associated with rumors (Goldhaber, 1986, p. 181).

However, in separating organizational communication in this rigid fashion, whyte (1969) cautions that we may have dichotomized the formal and informal communication structures in organizations to a degree that can be misleading: "In fact, it may be a characteristic of the most effective superiorsubordinate relationships that formal and informal elements are inextricably mixed" (p. 71). He also adds that dichotomizing all communication behavior into formal and informal may lead to confusion (p. 72). 
Mouzelis (1967) makes a similar point, telling us that "When one enters a concrete organization in order to observe closely the behavior of its members, it becomes extremely difficult to distinguish what is formal and what is informal in their actions" (p. 70). Providing in effect a resolution to the problems inherent in the formal-informal dichotomy, Downs (1967) divides communication in organizations into three categories: formal, subformal, and personal (pp. 113115). Formal has the same official meaning as in other taxonomies. Subformal, a new category first identified by Jones (1964), is divided into two subgroups: non-formal communications that use formal channels, and any communications that use informal channels. Personal communications are identified in terms of content: the revealing of the communicator's own attitudes as opposed to his or her official views as an organizational functionary.

Downs states that in organizations, subformal communications have great advantages because they can remain unofficial: ". . hence they can be withdrawn, altered, adjusted, magnified, or canceled without any official record being made. As a result, almost all new ideas are first proposed and tested as subformal communications" (p. 113, emphasis added). 
As discussed earlier, diffusion of innovations has been studied with an emphasis on network relationships and channels. Outside of this network analysis, however, the communication which deals with all aspects of innovation has not been studied at a micro-level so as to enable communication scholars to typify, categorize, or theorize about the innovation communication of organizations. In the process of studying the different messages in an organization, in particular those that are subformal, it is anticipated that a theory of innovation communication will emerge.

Innovation communication, defined by Cheney, Block, and Gordon (1986) as "all oral and written messages concerning an innovation" (p. 214), has been limited to treatment of the innovation as the critical message, with most studies focusing on how the innovation was communicated to members of an organization (p. 214). Cheney, Block, and Gordon, in their study of innovation communication in service organizations, offer a reconsideration of the Mills and Margulies (1980) typology of service organizations. However, this typology focuses on functional aspects of communication, such as task, maintenance, and personal functions. Again, what is lacking is the close scrutiny of all communication in an organization 
engaging in innovation, in order to develop conceptual categories and properties of innovation communication.

Account Analysis

For one source of data, this study used account analysis as a method to solicit and analyze the actions of collateral organization members and management decision-makers, in order to deepen the understanding of events taking place in the field.

As Harré and Secord (1973) explain, an account is an actor's own statement explaining why he or she performed a specific action (p. 9). Essentially, "an account is used to communicate one's preferred meanings about the event in question" (Buttny, 1985, p. 58). Accounts have been used as a data gathering method by many previous researchers. For instance, scott and Lyman (1968, 1970) used accounts to evaluate functions of managing problematic situations. Geist and Chandler (1984) and Tompkins and Cheney (1983) have both used accounts to study decision making. McLaughlin, Cody, and Rosenstein (1983) discussed accounts as a means of managing failure events. Finally, Buttny (1985) examined how individuals used accounts to reconfigure an event's context. Buttny (1987) also offered an overall analysis of how individuals structure and 
sequence events in their accounts of an episode. Although many researchers have narrowed the interpretation of accounts to mean only those that take place to justify or excuse a failure event, this researcher has used the broader definition of accounts offered by Geist and Chandler (1984): "Accounts are considered to be reflexive commentary which explains action" (p. 70). One uniqueness of this study is that account analysis has never before been formally used as a method to study the process of innovation diffusion.

\section{BACKGROUND TO PARTICIPANT OBSERVATION}

In describing how to do qualitative field work, Bogdan and Taylor (1984) state that participant observation, the major data gathering device, is "research that involves social interaction between the researcher and informants in the milieu of the latter" (p. 15). This broad definition covers a range of specific relationships. The participant may be relatively similar to or different from those observed, but the general relationship still qualifies as participant observation. In fact, in the course of this study, the author started out without any particular relationship to any of the collateral organization members, but she slowly over time 
became more a member of the group and less an external observer. But no matter what her exact level of involvement, the author was within the range of activity described by Bogdan and Taylor as participant observation.

Bogdan and Taylor also warn that the researcher should carefully guard her field notes and strictly maintain confidentiality, which is almost always a condition of being allowed to observe in the first place (p. 35). They warn that these confidentiality requirements will often result in the use of pseudonyms and other devices to mask the actual persons and organizations involved (p. 40).

In carrying out this research, the above prescriptions have been followed. In May of 1988, the author entered into an informal agreement with certain management personnel at a small silicon valley, California, defense contractor, which will hereafter be referred to as Defcon. This agreement allowed the author access to the facility for the purpose of observing the deliberations of a specific collateral organization working on the problem of improving the firm's process of submitting proposals to the government. From May of 1988 until the organization disbanded in December, the author was invited to 
observe all their deliberations and given access to all of the documentation concerning the history of the proposal submission problem, previous unsuccessful attempts to solve it, and the organization and tasking of the collateral organization itself. The author attended virtually all of the collateral organization's meetings, had free access to all of the members in private interviews, both formal and informal, and to the upper management of the firm, including the individual who formed and charged the collateral organization.

The organization selected specializes in highly classified electronic work, of a degree of technical sophistication beyond the author's ability. Prior to January of 1988 the author knew no one at the facility. Throughout the period of observation the author was careful to avoid taking sides or even offering opinions on the matters debated by the collateral organization.

None of the members of the collateral organization was aware of the nature of the study, but knew simply that a graduate student at a local university was doing work in the Communication Studies Department.

A strict confidentiality concerning the names of the company itself and the individuals in it was 
carefully maintained, as was agreed upon before the research started. Thus, all nar.es used in this research are fictitious and bear no resemblance to the actual names. The documentation and details of names, places, and other revealing particulars in all company materials cited and exhibited in this research are similarly altered to reflect these necessary changes.

\section{SPECIFIC SETTING FOR THIS STUDY}

How Defense Contractors Do Business with The Government Many sources have stressed the importance of understanding the background or context of an innovation prior to attempting an analysis of the communication surrounding the innovation. For instance, the Handbook of organizational Design warns, "One cannot hope to understand the fate of [an] innovation--its diffusion, adoption, and effectiveness--without understanding both the context out of which it was born and into which it is being introduced" (Kimberly, 1981, p. 95).

The context in which the Defcon collateral organization was formed, and into which its subsequent innovations were implemented, was one of turmoil and frustration surrounding the proposal process. Like many defense contractors, Defcon had been successful in 
the post-war years as a sole source supplier to the government. This environment allowed a contractor to be casual, non-structured, and inefficient in the writing of proposals. The Defcon proposal environment, not atypical in the industry, is epitomized in a statement made by Christians (1985): "The lack of competitive forces and the ability to get access to financial resources through acquiescent taxpayers, present a devastatingly inefficient environment . . ." (p. 70). In fact, the proposal process at Defcon was hit and miss because there was no incentive for it to be otherwise. The environment was exemplified by "envelope" proposals, bids made by contractors for multimillion dollar jobs, literally written on the backs of envelopes by engineers pulled off their regular assignments for a few minutes to put such a bid together.

The environment began to change in the late $70 \mathrm{~s}$, as public pressure escalated for less waste in government and public outrage mounted over $\$ 700$ coffee pots and $\$ 1,250$ toilet seats. In response to the public outcry, in 1984 the government enacted the Federal Acquisition Regulations (FARs), which introduced sweeping changes in the way the government procures goods and services. Suddenly, the premium was on effective proposals in a 
highly competitive environment. Companies unprepared to write effective proposals suddenly found business declining. The only answer was to learn how to write proposals better.

The major point of the FARs is the belief that the government will be best served by forcing contractors to compete against one another for government jobs. The FARs set up elaborate procedures for these competitions, which the contractors must follow. The essence of these competitions is that for each potential job, each contractor who wants to compete submits a formal proposal, which answers certain requirements for that job as specified by the government. The government evaluates each competitor's proposal, not against the others, but against the government's own stated requirements, and then makes an award to the contractor whose proposal is judged best. The crucial fact is that the government does not make the award to the best contractor necessarily, but to the best proposal. Hence, especially since the FARs, the ability to write effective proposals is crucial to any company wishing to do business with the government. In addition to technical or content problems in its proposals, a contractor may also have presentation problems, such as being unclearly or ineffectively 
written. In other words, a given proposal may fail to communicate what is wanted or intended by the contractor. Such failures of communication have plagued this particular contractor for many years. Throughout 1988, Defcon was engaged in a major internal effort aimed at improving its proposal preparation efforts. This effort centered on the formation of a collateral organization and a series of activities planned and implemented by that organization.

However, new approaches to old problems often fail to generate a positive response. Thus, although most people at Defcon recognized the proposal problem, they did not initially view the collateral organization as a real solution. In fact, many interviews and memos indicated an attitude toward the collateral organization as just the latest in management's ineffective solutions. In particular, it was well known at Defcon that most task forces appointed to solve a problem generally fail to accomplish their task. Because a task force is one form of collateral organization, the bad press associated with task forces was initially applied to the Defcon collateral organization. There are countless examples of the validity of the general impression of task forces as 
ineffective, notably the example given in the book In Search of Excellence. Peters and waterman (1982) studied a $\$ 600$ million sector of a several billion dollar company and inventoried the number of task forces (pp. 127-132). They found 325 task forces formally in existence, and after looking at each one they concluded that "Not a single task force had completed its charge in the last three years. Not a single one had been disbanded either" (p. 128). This finding underscored the generally negative view of task forces as inefficient and unproductive. However, as March (1981) predicts, "Although organizational response to environmental events is broadly adaptive and mostiy routine, the response takes place in a confusing world. As a result, prosaic processes sometimes have surprising outcomes" (p. 563).

The surprising outcomes of the Defcon collateral organization were not only solutions to problems, but six innovations, five of which have been implemented, been diffused, and received confirmation of their effectiveness. At the close of the author's observations at Defcon in December, 1988, the implemented innovations had contributed to a $100 \%$ win ratio on the seven proposals on which they had been used. 
The six specific innovations recommended by the collateral organization are as follows:

1. A centralized marketing organization--This was the formation of a new group specifically charged to handle all marketing efforts, such as intelligence gathering, customer relations, and other preparatory tasks essential to having the right data on hand from which to write a winning proposal.

2. An automated decision making tool--This tool, developed by a member of the collateral organization, was a programmable expert system, which could be loaded with the proposal team's view of the current proposal being developed. The program would then determine the likely win probability (given the team's data) and recommend a bid or no-bid decision. The tool could also be used to analyze strong and weak areas in the proposal team's approach.

3. Use of proposal specialists--This was the hiring of professional proposal writers to work every step of the way with existing Defcon technical personnel. These specialists were responsible for implementing and enforcing the new proposal methodology. 
4. An automated proposal methodology--This was a computer-based training system, which covered every aspect of the proposal process. A proposal manager could use the system to monitor the proposal team's progress, determine the next appropriate steps, and implement those steps. This automated methodology was a direct outgrowth of the automated decision making tool.

5. A proposal library--This was a library dedicated just to proposals, containing such things as generic proposal volumes for re-use, lessons learned from past proposals, customer and competitor profiles, and in general things typically used repeatedly on each new proposal. The idea was to re-use the output of effectively written proposals on later proposals.

6. Modernized proposal development facilities-This was the creation of an entirely new proposal development complex, with extensive new computer and publication hardware. The facility also included space for performing the various steps of the new proposal methodology, such as storyboard rooms and terminals for the proposal library. The main idea here was that everything needed for effective proposal development and 
publication would be in a single, integrated facility.

This study examined the communication that one specific group (the collateral organization) took to resolve a specific communication problem (the poor proposals), which resulted in a new approach to proposal writing and the facilities to support that approach (the innovations). All of the actors involved, except for this author, were dependent for their livelihoods on the solution to this communication problem. 
CHAPTER II

METHODOLOGY

FIELD STUDY

As discussed in Chapter one, the major thrust of this study is to examine the innovation communication from the point of view of the participants in that setting--specifically, to be able to see organizational innovation as people in the organization see it. The purpose, again, is to generate propositions for innovation communication in a collateral organization.

The specific methodology appropriate to the research problem under consideration in this study is the descriptive field study, which has been thoroughly examined and defined by Redding (1970, pp. 105-159), who specifically attacks "the stereotype of field research as preliminary or second rate" (pp. 146-147) and concludes:

A field study, then, is simply any kind of research carried out in a specified locale which is perceived by specified perceivers (particularly the subjects) as being free of significant researcher related deviations from everyday life. It may have any conceivable design, any conceivable controls, and any conceivable data gathering techniques available in the entire repertory of science. (p. 150) 
Zelditch (1970) also discusses the field study at length (pp. 495-511). Mowday and Steers (1979) have stated categorically, "Clearly the majority of studies carried out in the area of organizational behavior are field studies" (p. 115). Child and Smith (1987) also conclude that what they call "the fine-grained case study" is an excellent method through which to examine organizational changes in process (p. 565). Thus, the field study remains today a valid method overall, specifically the best approach to take for the particular problems being examined in this study. Schwartzmann (1986) outlines an approach which makes explicit several requirements of the researcher who is proposing to carry out a field study:

1. Researchers must allow the research problem to develop, evolve, and even change dramatically during the study, and likewise methods appropriate to the problem must be allowed to develop, evolve, and change.

2. Researchers must be willing to allow themselves to function as the major instrument of the study. Investigators' reactions to differences between their culture and the informants' culture are important.

3. Researchers must be willing to collect and handle contextually rich data that have been collected from multiple sources and by multiple techniques. 
4. Researchers must be willing to search for the informants' point of view while at the same time attempting to examine what is unproblematic to (and often not articulated by) the informant (p. 241).

\section{Grounded Theory}

This study seeks to generate grounded theory, using techniques which have been most fully described by Glaser and Strauss (1967). Essentially, their approach involves the researcher attempting to generate a theoretical explanation for an interrelated but diverse set of phenomena. The researcher seeks to discover underlying similarities among the diverse data. These underlying similarities provide the basis for the grounded theory which explains how the apparently diverse data can be viewed as related. It follows that as more and more data are generated, the theory generated may have to be adjusted to the latest information.

The specific approach Glaser and Strauss identify is the constant comparative method. In this method, the researcher gathers large amounts of interrelated data and then identifies relevant properties through which the apparently unrelated data can be sorted. These properties identify groups in terms of some 
commonality which serves to justify putting individual items into a particular group. By gathering items with similar properties, the researcher then identifies categories, which serve to systematize the data. A property is an identifying feature of a communication, on the basis of which that item is placed in a category. Thus, Glaser and strauss identify the basic rule for the constant comparative method as: "while coding an incident for a category, compare it with the previous incidents in the same category" (p. 106). An incident is thus any particular coded property, which by virtue of that coding is assigned to a category. The constant comparative method has four major stages, as identified by Glaser and Strauss (1967):

1. comparing incidents applicable to each category (pp. 105-108)

2. integrating categories and their properties (pp. 108-109)

3. delimiting the theory (pp. 109-113)

4. writing the theory (pp. 113-115)

In searching for data from which to generate theory, Denzin (1978) identifies three criteria: "First, there must be multiple instances of the behavior: second, the behavior must be repeated frequently over time and in different contexts; and 
third, the pattern must be based on publically observable acts and activities" (pp. 103-110). Glaser and Strauss summarize the constant comparative method:

Using the constant comparative method makes probable the achievement of a complex theory that corresponds closely to the data. . . This is an inductive method of theory development. To make theoretical sense of so much diversity in his data, the analyst is forced to develop ideas on a level of generality higher in conceptual abstraction than the qualitative material being analyzed. He is forced to bring out underlying uniformities and diversities (pp. 113-114). This study used a diversity of data from a single location, Defcon, to generate grounded theory concerning the interrelationship among the collateral organization, communication in that environment, and resulting innovations.

The setting for this Research

Campbell, Daft, and Hulin (1982) state seven guidelines for significant research, the first of which is crucial to the setting: "Significant research is an outcome of investigator involvement in the physical and 
social world of organizations" (p. 107). In other words, if the researcher selects a setting in which she cannot attain this level of involvement, all the rigorous methodology in the world will be of no value. The person who grants the researcher permission to study the organization is called the gatekeeper (Bogdan and Taylor, 1975, p. 31). In March of 1988, while evaluating a consultant at Defcon Corporation in Northern California, the author approached the business development manager of one of the two divisions of the company with the request to use Defcon as the field site for her thesis. This manager readily agreed to the proposal, so long as it used no names or in any way revealed the true identities of Defcon or any of its personnel.

Defcon was an ideal choice for the research because, as the author learned from the outside consultant, it was experiencing a serious communication problem, specifically the increasing dissatisfaction of the government (Defcon's major customer) with Defcon's proposals. Furthermore, Defcon had already tried several solutions to this problem, specifically, the use of two different outside consultants. Each of the two consultants was hired by different parts of the company and took radically different approaches to 
solving the problem. The first, hired at the company-wide level, wrote a report describing the proposal problems in general terms and recommending that his consulting firm be hired to do more work. The consultant's report was not inaccurate, but its contents were already well known to Defcon before the consultant arrived and it did not provide any specific or immediately implementable solutions. The second consultant was hired by one of the working business areas (profit and loss centers). This consultant took the approach of actually taking the lead on writing one of Defcon's crucial proposals. The consultant's methods were excellent and a high degree of enthusiasm was generated by the Defcon personnel who worked with the consultant. The team submitted an excellent proposal.

Unfortunately, the proposal lost, and the consultant's bill was for $\$ 50,000$. The high expense of this method made it unacceptable to Defcon's management. Even had the proposal won, it was clear that the company could not afford to invest an extra $\$ 50,000$ in every proposal. It was evident that an internal solution had to be found to the proposal problem. Defcon was thus ready for the introduction of a collateral organization of internal players to solve 
the problem. This in turn was a perfect opportunity for the author to observe this collateral organization from beginning to end.

SPECIFIC METHODOLOGY FOR OBSERVING THE COLLATERAL ORGANIZATION AT DEFCON

This study focused on the formation and activities of the collateral organization at Defcon. This organization was specifically charged to solve the proposal submission problem at Defcon.

\section{Sources of Data}

The collateral organization was formally charged on May 31, 1988 and started weekly meetings the following Tuesday. They continued meeting for six months. The author attended virtually all of their meetings, and also had regular interactions with all members of the collateral organization outside of the weekly meetings. Copious notes were kept of all visits to Defcon, which included both weekly meetings and off-line interviews with the members of the collateral organization. The author also met with other Defcon personnel either in the management chain or otherwise affected by the proposal submission problem and hence by the collateral organization. In addition, she was 
given access to all the written materials provided to and written by the collateral organization. All of her notes, plus all of the written Defcon materials constitute the research text of this study. These notes are not recorded transcripts, but are exact except for minor changes to remove fillers and redundancies. The author gathered data on the collateral organization over a six-month period, from May, 1988, through December, 1988. The data were gathered through at least weekly visits with the members of the collateral organization. This length of time provides a longitudinal view of the development of the problem and its solution.

Data were gathered from multiple sources, all addressing the same proposal problem. These sources included the following:

\section{Interviews}

Bogdan and Taylor (1984) have defined the in-depth interviewing typical of qualitative methods as ". . repeated face-to-face encounters between the researcher and informants directed toward understanding informants' perspectives . . " (p. 77).

over a six-month period, the author conducted indepth interviews with 30 Defcon personnel, including members of the collateral organization, 3 members of 
senior management, and 8 individuals working on specific proposals at Defcon (but not in the collateral organization). These interviews ranged in length from 15 minutes to 3 hours, and covered all aspects of the Defcon proposal problem; various past, present, and future solutions to that problem; and the collateral organization's involvement in the entire process. Some of the interviews at off site locations were audiotaped; however, because of security sensitivity at Defcon, most interviewees were not comfortable with tape recorders. The author recorded these interviews as precisely as possible with non-electronic means. Following Bogdan and Taylor's advice, the author relied heavily on probing the informant for clarification, rephrasing statements made and asking for confirmation (1984, p. 97). This probing into the informant's justifications for actions and decisions was an important aspect of generating accounts and the resulting texts from which the author drew conclusions.

Notes from these in-depth interviews were first ordered chronologically with the other sources of data, matching the person with the event in question. Both the summaries and the initial notes were then closely read, annotated, and coded. 


\section{Participant observation}

Bogdan and Taylor (1984) comment that ". . participant observation provides a yardstick against which to measure data collected through any other method" (p. 79). Participant observation provides the foundation for qualitative work, in that many of the most important principles inherent in qualitative methods are fulfilled. The constant comparative method being used in this study involves close and personal inspection of the action being observed. These observations are then built inductively into tentative conclusions which satisfactorily account for all the observed data.

Also, the constant comparative method allows the observer to witness firsthand the events in question, but the individuals being observed are more concerned with their own activity than with the fact that they are being observed. The observer's proximity implies that the observer is close, but does not change the action being observed (Van Maanen, 1983, p. 255). The author participated in the sense that she was overtly present at meetings, as opposed to hidden, but not in the sense that she was actively involved in the substance of the meetings she observed.

The author observed every collateral organization 
weekly meeting over a six-month period from May through December, 1988. During this time period, approximately 25 meetings were held. The scheduled time for each meeting was two hours, and most of the meetings lasted exactly that long. For the same security reasons as applied to the interviews, tape recorders were not used, but instead the author took notes during the meetings. The same summary, annotation, and coding procedures used on the interview notes were also used on the meeting notes.

As part of the collateral organization activities, numerous separate small group meetings were also held. Some of these involved subsets of the collateral organization itself, and others involved just one or two collateral organization members interacting with larger groups of other Defcon employees. On a few occasions, these extra meetings also involved non-Defcon personnel, such as competitor or government employees. The author observed approximately 50 meetings outside of the regular weekly collateral organization meetings. These meetings lasted from a few minutes to several hours, with most taking from 30 to 60 minutes. The same summary, annotation, and coding procedures described above were also used on the notes from these meetings. 
On several occasions, members of the collateral

organization were required to brief upper management on the progress of their activities and the recommendations at which they are arriving. The author attended approximately five such briefings, each of which lasted about one hour. The same summary and annotation procedures described above were also used on the notes from these briefings.

\section{Documents}

Bogdan and Taylor (1984) state that records and documents " - - lend insight into the perspectives, assumptions, concerns, and activities of those who produce them" (p. 120). The records and documents examined provided a background and historical perspective on both the company and its proposal problems. Also, documents were produced by the collateral organization, which provided direct insight into its communication.

The author was allowed access to numerous Defcon internal documents relating to the the history of the company's proposal problem. These documents included the written reports of the outside consultants hired to work on the Defcon proposal problem before the collateral organization was formed. These documents 
also included internal memos on the proposal problems going back approximately four years prior to the formation of the collateral organization. The internal and external documents on the proposal problems total approximately 200 pages.

In addition, the collateral organization itself generated weekly minutes of its activities, plus numerous briefings and presentations and the raw material behind those finished products. The collateral organization also gathered large quantities of written materials relevant to the proposal problems, such as past proposals, various proposal training materials, and proposal development materials from competitors and from the government. The author had access to all these written materials and made copies of the most central ones. The written materials, including all of the above, total approximately 1000 pages, of which the author copied and annotated approximately 300 pages.

\section{Analysis and Coding}

The overall goal of the analysis and coding effort was to categorize the communication used by members of the collateral organization in the process of diffusion of innovation and to explain what features of that 
communication seemed to be associated with successful and unsuccessful innovations. Based on this analysis, grounded theory could be developed to explain why certain categories of communication worked while others did not.

Many different efforts were directed at ordering and systematizing the large amount of data gathered. Many of the preconceived notions and theories about the direction that the data would take were dispelled in this process. The process revealed that the communication that took place in the collateral organization before its first successful innovation was distinctly changed in the successive innovations. Because of the observable differences of the communication in the events before and after the first successful innovation, the data from these two phases were separated into two large categories: before acceptance of an innovation and after acceptance. The data were then further divided within both the before and after acceptance categories. Due to the fact that properties of messages gleaned from the four sources of data were different, it seemed wise to separate them for analytic purposes into four categories: 1) collateral organization meetings; 2) briefings to upper management; 3) written 
communications, including collateral organization meeting minutes, and memos; and 4 ) accounts gleaned from interviews with collateral organization members and management decision-makers.

Accounts, the fourth source of data, were generated from the interviews of participants in order to uncover the motives underlying the innovation communication in the collateral organization.

The definitive statement of account analysis as a research methodology in the field of communication is provided by Tompkins and Cheney (1983). The essence of their discussion is that because the researcher is interested in observing behavior and interpreting the reasons for it, the first step, which account analysis is intended to perform, is simply to ask the participants to explain, or account for, their behavior from their own point of view (pp. 129-130).

The author sought validation of her interpretation of events from the participants. This approach to validation is described by Tompkins and cheney (1983) as negotiation between observer and participant ( $p$. 130). Specific validation procedures included confirming researcher interpretations during formal interviews, as well as informal questioning of participants to clarify prior written and oral 
communications.

Once a workable and stable framework was located in grounded theory, the data were manually sorted into coding categories by cutting up copies of the field notes and interview transcripts and placing individual pieces of data in separate folders corresponding to the source of the message: meetings, briefings, written documents, and accounts. If a single datum corresponded to more than one code, multiple copies were made and placed in the appropriate folders. Because some data were still left uncoded, additional coding categories were developed to maximize the amount of data used. Uncoded data were assigned to one of two categories: historical information relevant to the narrative context, and unused data. Most of the unused data were either highly technical in nature or concerned with specific personalities or historical events not of general relevance to the innovation communication being studied.

The coding was carried out utilizing the framework provided by Glaser and Strauss (pp. 105-113.) The author coded each incident in the data into as many properties or characteristics as possible, and then integrated them into categories. This coding was done on the margins of the typed field notes and documents. 
The coding was constantly compared, re-evaluated, and either re-coded or re-confirmed, in an iterative sequence as new data was generated. Glaser and strauss stress that two types of properties emerge: those that the researcher has constructed herself, and those that have been abstracted from the language of the communications (p. 107).

By constantly and methodically comparing the codes of each incident or episode, a gradual generation of theoretical propositions began to emerge. The coding scheme allows the researcher to examine each piece of data not as an isolated event, but as an example of a category of events. As the researcher notices that events in certain categories consistently have similar associations, she is able to capture that consistency in the form of a proposition, which draws a general conclusion about the individual items in a given category. As Glaser and Strauss predict, "The analyst starts thinking in terms of the full range of types or continua of the category, its dimensions, the conditions under which it is pronounced or minimized, its major consequences, its relation to other categories, and its other properties" (p. 106). The next step consisted of integrating properties and their categories. For instance, this study 
identifies the category of "selective disclosure," which has properties such as "strategy," "misinformation," and "ambiguity." Instead of comparing incident with incident, the author compared property with property. In addition, as predicted by Glaser and Strauss, as the different properties became integrated, a new code resulted that would encompass the broader characteristics of the property.

The last step, delimiting the theory, occurred at two levels. As the theory concerning innovation communication took shape, there were fewer modifications of the codes. Also, reduction of the total number of codes occurred, caused by the researcher's ability to see underlying uniformities in the properties and categories.

\section{Limitations}

The most common concerns about qualitative methods in a research project are concerns about objectivity and about generalizability (Patton, 1987, pp. 166-167).

Although the problem of subjectivity could be applied to any and all research methods, its potential skewing of the interpretation of events looms large in studies based on "participant" observation. The basic problem is that the researcher becomes an actor in the 
act to be described. The length of time the author spent at Defcon made objectivity difficult to maintain. Becoming in effect a member of the collateral organization resulted in cooperative and friendly informants, but also in a potentially subjective researcher. However, this is expected when taking a phenomenological approach and looking at organizations from an interpretivist point of view.

In terms of generalizability, the constant comparative method does not attempt "to ascertain either the universality or the proof of suggested causes or other causes. . . [It] requires only saturation of data" (Glaser and Strauss, 1967, p. 104). The constant comparative method is limited in that it is not generalizable, but that is also its strength--it does not attempt to prove theory beyond its own data. Instead, it generates a theory that is empirically grounded.

One final limitation is that this presentation of data is limited to formal meetings, briefings, and interviews, leaving out many informal events that nonetheless had an impact on the overall success of the Defcon collateral organization. These informal factors could not be considered because this author did not have access to many private and unplanned events. 
CHAPTER III

THEORETICAL PROPOSITIONS CONCERNING INNOVATION COMMUNICATION IN THE COLLATTERAL ORGANIZATION This chapter will present grounded theory in the form of propositions about innovation communication in the collateral organization, based on the author's observations and interactions at Defcon. First, the overall theoretical perspective based on the phenomenological grounding of this study will be presented. This will serve to establish the context in which the specific propositions resulting from this study will be developed. Next, the derivations of these specific propositions will be explained, using the data gathered throughout the 6-month history of the collateral organization. Included in the data used to generate and support these propositions are the author's observations of various collateral organization meetings and briefings, the written documentation generated by the collateral organization, and the results of interviews conducted with various Defcon personnel.

THE CREATION OF SHARED REALITY

At the outset, the collateral organization was a collection of individuals from many areas in the 
larger Defcon organization. The locations from which the various members came are shown in Figure 1 and $a$ list of the major participants is provided in Figure 2. In many cases, these individuals did not even know each other before being introduced at the collateral organization's first meeting. Through the collateral organization, this disparate group of individuals created a shared reality, which was a necessary precursor to their getting any work done, or even their ability to talk meaningfully to each other.

Eventually, after the collateral organization had created an identity for themselves, they had to project a view of reality on to the larger organization. This projected view did not have to be identical with the collateral organization's own view, and often wasn't. But it did have to be some view that was useful in gaining management acceptance for the innovations presented by the collateral organization. The creation and projection of shared realities is fundamental to the phenomenological ground of this study, and as the propositions revealed in the data indicate, also fundamental to the success which the collateral organization enjoyed in getting acceptance for their innovations. The major events in the six-month history of the collateral organization are shown in Figure 3. 




SIMPLIFIED DEFCON ORGANIZATION CHART

FIGURE 1 


\author{
NAME POSITION IN \\ LARGER \\ ORGANIZATION \\ FUNCTION ON \\ COLLATERAL \\ ORGANIZATION \\ 1. Jack Johnson \\ Division 1 \\ Formed \\ Executive \\ Collateral \\ Organization, \\ which reported \\ to him \\ 2. Ted Clarkson Junior Engineer, \\ Business Area in \\ Division 1 \\ Leader of \\ first phase: \\ creator of \\ automated \\ decision \\ making tool
3. William Siddoway
Staff to Division 1 \\ Leader of \\ second phase: \\ creator of \\ subsequent \\ innovations \\ 4. Bob Reese \\ Computer \\ Programmer in \\ Computer \\ Center \\ Technical \\ expert; \\ co-creator of \\ automated \\ decision \\ making tool \\ 5. Manny Fierro Technical \\ library staff; \\ Provided access \\ to past \\ Engineering \\ Directorate \\ proposals \\ 6. Diane Hill Editor, \\ Existing \\ Proposal \\ Center \\ Kept minutes; \\ joined Proposal \\ Support Group \\ (PSG) \\ Seven other individuals were also on the collateral \\ organization, representing both divisions 1 and 2 . \\ These members took a less active role and most \\ eventually dropped their membership in the collateral \\ organization.
}

\title{
Figure 2
}

KEY PLAYERS ON THE DEFCON COLLATERAL ORGANIZATION 


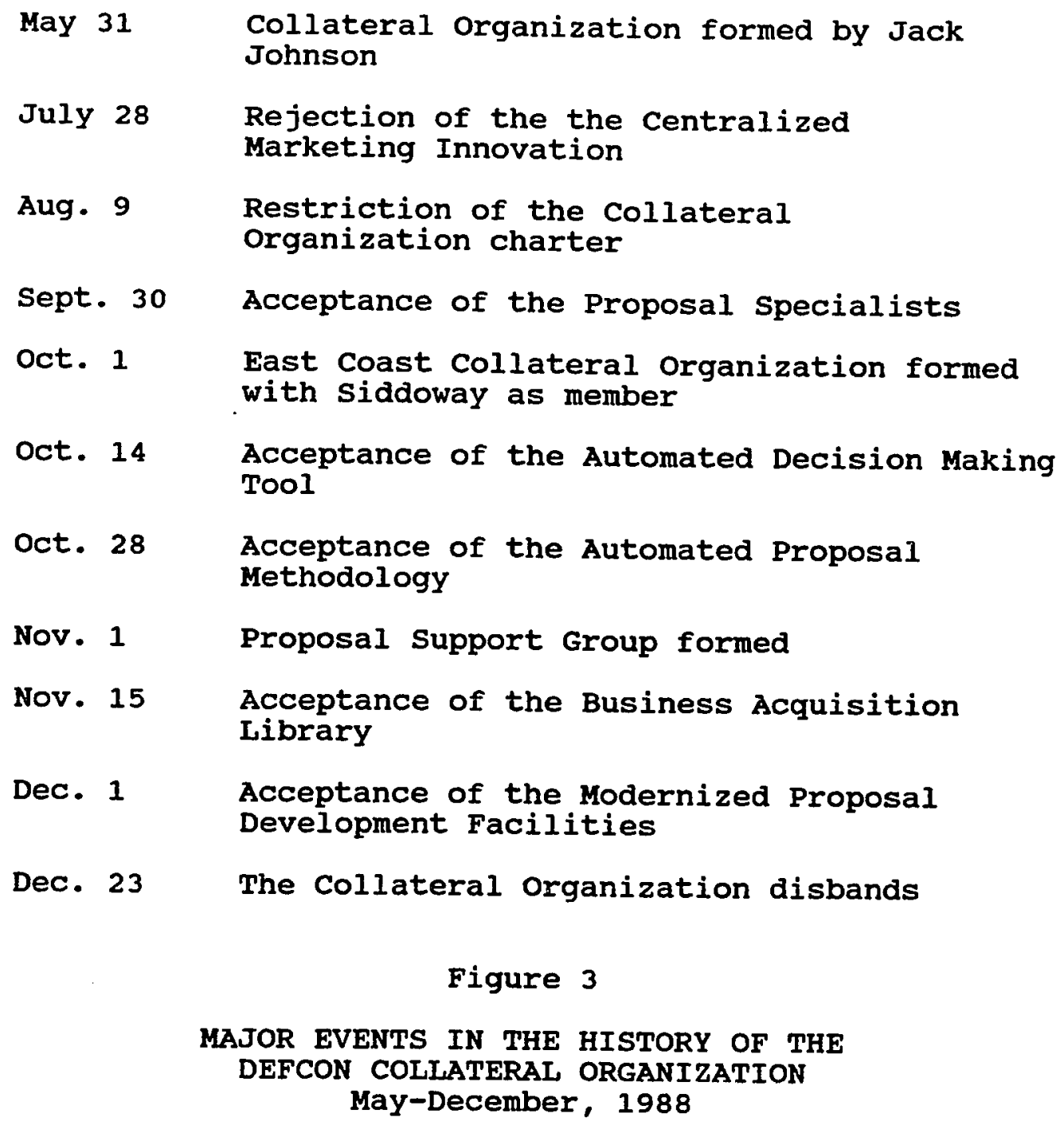


1. The collateral organization's communication was distinctly different before and after the first acceptance of a proposed innovation. Two watershed events took place in the history of the collateral organization. The first was the rejection of the collateral organization's first innovative proposal, a plan to create a centralized marketing organization. Before this event, the communication of the collateral organization members was tentative, as the group was still searching for legitimacy. After their first rejection, the group members' communication became emotional and cathartic. The second watershed event occurred after the organization successfully presented an innovation management liked and accepted, which was to identify a group of proposal specialists. This initial success seemed to confer a legitimacy on the group that it had not enjoyed before. Once the collateral organization had tasted success, its communication was used to define itself as a "bandit organization" existing outside normal organizational boundaries and restraints. Along with this new view of itself and its role in the organization came a new approach to communication, which was reflected in collateral organization meetings and briefings. With each change 
in the members' view of their own situation, their communication changed as well.

As the following propositions will show in more detail, the time before the first rejection was characterized by tentativeness in the communication of the collateral organization, as they searched for their proper role within the larger organization. That is, the members of the collateral organization seemed to be searching for a view of reality which they could share among themselves and which could provide legitimacy for their innovative efforts.

The second stage, between the rejection of the first proposed innovation and the acceptance of the second, was characterized by emotional and affective communication, which was virtually absent from the first stage. During this period, the members of the collateral organization were actively defining themselves and their reality. Their gaze was turned inward, on their own reactions and emotions in response to what they felt was an unfair changing of reality by management in rejecting their first innovation. Since, from the member's point of view, the rules had been changed, they had to decide as a group how they were going to respond to this new world.

In the third stage, the communication of the 
collateral organization was typified by a "bandit" mentality, as the members defined themselves and their reality as exclusive members of a sort of officially sanctioned counterculture, licensed to interact with things beyond the limits under which ordinary people worked. This view of themselves provided a sense of power, legitimacy, and freedom, all of which typified the communication of the collateral organization throughout the time after its first successfully proposed innovation. This new power and legitimacy in turn led to more accepted innovations and still more "bandit" communication among collateral organization members. Eventually, the collateral organization was legitimized and worked into the larger official organization on a permanent basis, so they were no longer bandits free to prey on the larger organization.

2. The tentative communication of the collateral organization indicated a searching for identity and establishing of legitimacy.

Kanter (1988) extols the creative possibilities of "multidisciplinary project teams" for generating innovations. She states that the "loose boundaries, open communication, and flexibility" that this type of group has available sets the stage for innovation 
(p. 178). However, the special strain and uncertainty inherent in the "looseness" have not been taken into account. In fact, it seems natural that an ad hoc group would feel uncertainty about its exact mission and role within the larger organization. This uncertainty is in effect an identity crisis, which cripples the group until it can come to grips with its own nature and legitimize itself. Only then can the group do anything in the larger organization.

In newly formed groups, each of the group members to some extent leaves behind his or her prior organizational identity and thereby experiences uncertainty about the new and often unstated expectations inherent in the new situation. A group in this situation will often experience uncertainty concerning its mission, its role in the larger organization, and its exact latitude and power in that larger organization.

In the case of the collateral organization at Defcon, this problem was particularly acute. The communication norms at Defcon involve polarization and secrecy due to the nature of their products and their entire industry. Thus, organization members are accustomed to working together for short but intense periods of time, but always with a clearly defined 
mission already established and a specific methodological approach pre-defined as well. The collateral organization examined in this study had a clear mission, but did not have a pre-defined methodological approach to that mission. Furthermore, because of the compartmented nature of the work, members from one division rarely work with members from another division. Thus, while the goals may change, the players usually remain quite constant and the marching orders quite clear. The result is that group identity and methodology are usually not factors the group itself has to work out.

The hierarchical mixture of levels among collateral organization members was therefore a new and troubling hurdle for most individuals to cross. The fact that the group members came from such diverse levels of the company, were not told why they had been chosen, and seemed to be cast somewhat adrift made uncertainty inevitable. The result was an initial tentativeness and searching for a shared reality from which the group could work. This was reflected in the organization's initial communication.

The first meeting of the collateral organization foreshadowed the type of communication that typified meetings during the time the group was still searching 
for organizational legitimacy. This implies both legitimacy in terms of an accepted role within the larger organization and legitimacy in terms of the collateral organization's own view of itself and the organizational reality around it. In fact, it appears that the first task of the collateral organization is to win the right to take itself seriously. The members felt they needed to generate enough legitimacy that their recommendations would be listened to and acted upon.

As members introduced themselves in the first collateral organization meeting, each one of them made some kind of reference to his/her uncertainty about this new organization. Because they came from wide-ranging areas of the company, most of them were meeting for the first time. Also, Mr. Johnson did not attend this or any other meeting, which left them to work out their roles on their own. Presumably, he knew who they were and why they were there, but he didn't share this knowledge with them.

Thus, the initial communication was tentative, exemplified by several of the members as they introduced themselves at the first meeting: "I'm Diane Hill, the editor over at the Proposal Center. I'm not sure why I'm here or what I'm supposed to do, but I'm 
sure that'll come clear," or "I'm William siddoway. I'm not sure what's relevant about myself to what our mission is. . . Anyway, I'm sure we've got some serious problems to consider."

In the time before the first accepted innovation, the need to establish an identity was met by the technical specialists. They generated an enthusiasm and optimism that reassured the other collateral organization members. Mr. Clarkson, a respected and likeable technical specialist, took occasion to reassure the members that management was sincere in granting power and a free hand to the collateral organization, as revealed in this dialogue from the author's notes taken during the first collateral organization meeting:

BF: I'm skeptical. Is management really going to listen to us?

CZ: Of course they are. Look around you. There's a lot of money being spent here if they aren't going to listen.

TC: I'm sure they're gonna listen, but I'm also sure that we need to put the best possible product in front of them for our first report. They may only listen once, so the first thing we say had better be good.

JS: Well, I want more than 'you're sure.' I want 
action.

TC: We all want action. But the best way to get it is for us to do our part well. We have to believe in ourselves first, before they can believe in us.

In this dialogue, TC is Mr. Clarkson, who assumed leadership for the first phase of the collateral organization's activities. He consistently displayed this reassuring tone with other members, who were uncomfortable with the fuzziness of their charge to solve the proposal problem. Task forces were viewed with suspicion and a collateral organization had never been heard of before by most of the members. The members of the collateral organization were thus faced with the initial task of defining just who they were in this new role and what they were supposed to do in it. In the time before the first accepted innovation, the level of uncertainty and caution remained high for most of the members, with the exception of clarkson himself.

All the meetings that took place during this time were filled with a questioning of the validity of the mission of the collateral organization. This amounted to a questioning of the reality on which the collateral organization was supposedly founded. It was as though the members thought they saw something, but like a 
mirage, they were not sure that it was real. Until they could test their vision, doubts lingered as to the internal and external credibility of the collateral organization. This uncertainty was expressed openly. Many of the members voiced uneasiness over being on a "collateral organization." As a junior technical specialist said, "It makes me uneasy to have my name on something I don't have a clue what it means."

The uncertainty that the members of the collateral organization felt both about their own organization and its place in the larger Defcon world is well

illustrated in the following dialogue:

DH: I can't justify my time here to myself or my boss unless we're productive.

FR: It's not that exactly. It's that I finally feel like we have the potential to fix some of the obvious messes. If we don't hurry we're not gonna get the chance, though.

TC: How're we not going to get the chance?

FR: I don't know about you, but every time someone asks me if we've come up with something, I think they're ready to stop this little experiment.

Both $\mathrm{DH}$ in the dialogue above and $\mathrm{CZ}$ in the previous dialogue mention time spent away from regular 
assignments. In fact, the group seemed to take great comfort from the fact that their presence on the collateral organization was costly. Perhaps this was a way of concretely measuring the level of real commitment on management's part to what they were doing. Zand (1981) tells us that one of the big advantages of a company using a collateral organization is that it doesn't require new people or resources (p. 58). But the reality is that the collateral organization members at Defcon were very aware of the time spent away from their regular jobs. In addition, their offices in the company billed Mr. Johnson's office for the time they spent on collateral organization business. Thus, their membership on the collateral organization was expensive, but that expense seemed to legitimize their role.

FR's reference to the collateral organization as a "little experiment" was representative of the uncertainty of the group about its role. Just in case the group was not successful, terms like "little experiment" also served to mimimize the group's potential and hence any individual's loss if and when it should fail.

Two communicative events occurred when the automated decision making tool was finished that 
demonstrated the uncertainty that the collateral organization members felt about their exact role and mission. Although the group seemed to feel that the expert system was a true breakthrough innovation, the most positive commentary about it that $\mathrm{Mr}$. Clarkson, the main inventor, could manage was that he was "cautiously optimistic" about its potential. There was no speculation about the fantastic applications or possibilities that the automated decision making tool presented. The reality level for the entire enterprise was not sufficiently strong at this point to support such speculation. Hence, the members had to be tentative in case the innovation failed through some unexpected disaster.

Second, rather than hypothesizing about its potential usefulness, the group decided that this innovation would not be presented to management. Instead, it would first be used in a practical demonstration of its abilities. Then the expert system would be presented jointly with whatever initial decision it indicated. This tentativeness and uncertainty resulted in the decision making tool itself being rejected for a time by management.

The leadership in the collateral organization also was symptomatic of the role uncertainty that existed in 
the group. Clarkson was never told that he was to lead the group, aside from reading about it in $\mathrm{Mr}$. Johnson's memo announcing the formation of the collateral organization. He was one of the youngest and least senior level employees on the collateral organization, but he was well-liked and optimistic. He expressed his surprise to this author about seeing his name in Johnson's memo as the identified leader, saying "At first I thought he'd made a major mistake. I'm the second most junior person on it."

However, after the rejection of the centralized marketing innovation, he relinquished leadership to $\mathrm{Mr}$. Siddoway. Because none of this had ever been discussed either formally or informally among the members, the author sought an account from clarkson about his new role in the group. In this account, clarkson's changing perceptions both of his role and the group's legitimacy as a whole are both evident:

SL: Do you miss not being the leader of the group anymore?

TC: In a way, it's great not to have the responsibility of leadership. I didn't really like being the leader that much. Johnson just seemed to want me to do it, so I did. Besides, I respect and admire Bill [Siddoway] so much 
that I'm confident that the group will

function even better with him as leader.

Clarkson seemed more secure in his role of non-leader than he ever did in the role of leader. This translated to less role uncertainty and ambiguity for him. Also, he probably spoke for the whole group by stating his confidence in siddoway as the new leader. Both Clarkson and the group as a whole seemed to feel better about the group's chances for success with Siddoway as the leader. The new leadership appeared to indicate a new role for the group, which most members felt would also be a more powerful and successful role. After the first meeting following the rejection of the centralized marketing idea, several members stayed behind to congratulate Mr. Siddoway on his emergence as leader and to promise their support for his efforts. In fact, the confidence the group felt in siddoway was quickly translated into successful results. In this case, the creation of an image of success despite the group's actual rejection quickly became a selffulfilling prophecy.

The uncertainty of both the personal roles within the collateral organization, and the uncertainty regarding the role of the collateral organization at Defcon likely had a positive effect on the subsequent 
innovations they created and implemented. Goodman and Goodman (1976) take this idea a step further by postulating that "role clarity" inhibits innovation" (p. 494)

Hedberg (1976) elaborates on that notion, by describing roles in ad hoc groups as "tents" rather than "palaces": "An organizational tent actually exploits benefits hidden within properties that designers have generally regarded as liabilities. Ambiguous authority structures, unclear objectives, and contradictory assignments of responsibility can legitimate controversies and challenge traditions. . . Incoherence and indecision can foster exploration, selfevaluation, and learning" (p. 45).

The collateral organization "tent" was not firmly staked to the ground in the first few months, resulting in an ongoing search for legitimacy that perhaps explains in part their enormous productivity. The uncertainty of just "who they were and what they were doing there" might also have contributed to the extreme opportunism that characterized both the communication and the activity in the last phase of innovations. 
3. The initial communication of the collateral organization questioned inferences and demanded evidence.

Gouran (1986) comments at length on the factors which he feels often result in poor inferences on the part of groups. These factors include a tendency to give credence to atypical information or to specialist sources of knowledge, and the construction of scenarios or scripts. Perhaps because of its heightened sense of uncertainty, the Defcon collateral organization did not suffer from any of these problems. Atypical sources of information and specialists were all put under the same rigid and skeptical scrutiny that the group extended to its own members. Scripts or scenarios were not presented as unsupported sources of evidence.

In the collateral organization's search for a shared reality through which they could support their efforts, hard evidence was an important source of internal as well as external legitimization. The shared reality within the collateral organization was that the organization was weak and its future shaky. This generally negative view was reinforced by the rejection of the collateral organization's first suggestion. Because of this lack of confidence, critical questioning and close analysis was valued. 
Atypical evidence was challenged, specialists were listened to critically, and rosy colored scenarios or scripts were held up to critical scrutiny. In fact, concrete evidence was a necessary component for virtually every assertion.

In addition to the organizational reasons for supporting assertions, the engineering background of most of the members implied that evidence or reasons were usually required to legitimize any opinion. The necessity for hard evidence is a standard part of an engineer's training and thus came naturally to virtually every member of the collateral organization. Hence, the innovation communication typical of the early time before the first accepted innovation was characterized by critical questioning and careful argumentative analysis, much more so than discourse in many other environments. Sometimes it sounded like one was in a court of law or under rigorous examination by a skeptical judge. When a member failed to supply reasonable evidence, he or she was met with statements such as those illustrated in the following passages from different meeting notes taken over a period of several weeks. In each case, after being challenged, the speaker would attempt to provide some sort of evidence to support the statement: 
BR: I think most people would agree with the idea that our proposals have been generally viewed as weak by the government.

WS: You can't prove that.

BR: But I've seen several consultants in here over the past three years telling us how bad they are.

DH: I just feel like we used to do it better before the new program was added at the proposal center.

TC: That's not logical.

DH: OK. Well, it is logical to notice that our win ratio's been going down over the past three years or so.

$\mathrm{DH}$ : Management just wants to keep the capital budget as small as possible, so they keep reducing all budgets across the board.

DD: It doesn't follow.

$\mathrm{DH}$ : I'm not saying it does. I'm just saying that's how management is justifying it.

ws: That's how they did it when they won their first big contract. 
DZ: That's not convincing.

WS: It's not just them. I know several other companies that do the same thing.

BF: I know the inductive approach will work.

TC: Prove it.

BF: I've seen it work lots of times in the past.

Two factors stand out about these comments. First

of all, in the first statement of each pair, the speaker is almost always tentative and hardly ever aggressive or confident. Phrases such as "I think" or "I feel" are used as hedges. Furthermore, if there is a firm statement, the speaker often attributes it to someone else, with phrases such as "That's how they did it," or "I'm not saying I like it, but . . ." Firm, unqualified statements were not the norm in this stage of the innovation communication.

Part of the reason for this tentativeness may be found in the second statement in each pair, which calls into question the first statement. These types of remarks were not stated with intention to hurt or reject, but more as a reminder to group members that the outside world was skeptical and likely to reject anything not firmly supported. In this sense then, the demand for evidence was more like a chant or 
incantation indicating shared membership in a skeptical and cautious way of looking at the world. Typical of this communication, at the end of the first meeting, Mr. Siddoway, a non-technical member of the organization, cautioned the group: "Don't bring in anything unless it's solid."

As another example, throughout the loading of the automated decision making tool, the communication process was marked by admonitions from each member to "be rational," "make it concrete," "gotta have a better reason than that," and the ever-present "let's don't waste time." As befits the skeptical nature of innovation communication during this time, this careful approach was used instead of a more openended brainstorming. The usual free-wheeling attributes of brainstorming were noticeably absent. The ground rule for acceptable communication was offered by Mr. Reese, the usually laconic computer programmer: "Don't anyone ever offer something that starts with 'I feel.' It's gotta be real, or it's not important to this group." (This was said while glaring at the sole female member of the group.)

With this remark, Reese made explicit what had been implicit until then: what was "real" for the collateral organization at this point was cognitive, 
and well-supported. Reality lay well away from personal or interpersonal concerns.

Perhaps because of admonitions like these, combined with the critical approach most members felt comfortable with, communication was cautious, and some of the members were often silent. In addition, those members who volunteered ideas for the automated decision making tool, did so without personal examples, and without any affective information as part of their rationale. Phrases such as the following were used in the meetings so that the seriousness and need for rationality felt by group members was still obvious: "from my experience," "based on other reports," "the most reasonable criteria," "for the long run," "the most systematic approach," "is realistically implementable," "objectifying our evaluation," and "detailed support and justification." These are representative of all the discussions uf to this point; characteristics evident in this communication are that arguments are reasoned, thorough, consistent, wellsupported, and serious. Unlike Gouran's finding of uncritical acceptance being given to atypical information, expert testimony, or scenarios and scripts, the members of the Defcon collateral organization rarely used and never accepted such 
argumentative devices. As the earlier example shows, when a member tried to use expert testimony and scenarios, such as "That's how they did it when they won their first big contract," the speaker was immediately asked for better evidence: "That's not convincing." Notice that the second speaker did not deny the validity of the first statement; he just asked for more convincing evidence.

Janis (1972) and Gouran (1986) make a case for the non-questioning of inferences by group members in decision-making groups. In fact, Gouran states that communication actually enhances the possibility for faulty decision-making, especially in the case of atypical information, in which the originally faulty inference is simply amplified by other group members. The collateral organization not only questioned inferences made by group members, they questioned even the most demonstrable facts. In effect, for the collateral organization, all data were atypical and all were open to questioning. Because everything was questionable, nothing was just allowed to slip by unchallenged.

The identification of the 57 most pressing proposal problems at Defcon, the narrowing the solutions to four categories, the weighing and ranking of criteria, and 
the hypothesizing about the possible outcomes all exemplified a methodical process for rational decision making.

4. The affective communication of the collateral organization released tension

and established cohesion. Following the rejection of the centralized marketing organization in July, the communication of the collateral organization was intensely affective for the first time. A full meeting was spent airing feelings about management's decision. Each member of the group felt he or she had to make a decision about the possibility of future rejections, and how that affected their continued membership in the collateral organization. The two members who were noticeably silent during this sometimes heated conversation were Mr. Siddoway and Mr. Clarkson. Neither of them took a vocal part in this re-evaluation process. Interestingly, one of the factors that seemed to fuel much of the negative emotion was Mr. Johnson's lack of rationale for the rejection. In other words, he didn't play by what the collateral organization took to be the communicative rules concerning concrete grounding. The fact that he had "no good reasons" to 
reject their tool was galling to most group members. He had told Mr. Siddoway and Mr. Clarkson that his "gut feel" was telling him to $\mathrm{nix}$ the centralized marketing innovation, and this remark was negatively elaborated upon by angry members. In fact, at one point the "gut feel" rationale of $\mathrm{Mr}$. Johnson's became the target of this negative comment: "Since his gut's so much bigger than his head, that's what he follows around." Cohesion was established both by the venting of feelings, and the caricaturing of $\mathrm{Mr}$. Johnson as one who was an authority figure and outside the group. The uncertainty about the value of their innovations was no longer present; they were now certain that their innovations were good, because the reasons by which they had been rejected were so poor.

The group's communication process up to this time had been so pointedly cognitive and reasoned, that this affective display seemed totally out of character with their past norms. The group's shared reality up to this time, which they had so carefully built and maintained, was rejected along with its innovations, but this simply became the impetus for the group to redefine its reality in a more useful way. For the first time, ties were loosened, most of the men's jackets were removed, and the group moved in 
closer around the conference table. It was a veritable "circling of the wagons" that demonstrated a drawing together against the "enemy" that had shot them down. Mr. Siddoway summed it up for the group when, after the outcry had dimmed, he drummed his fingers on the table and murmured, "No more Mr. Nice Guy."

The very next meeting held by the group brought forth the next innovation--a proposal specialists group. This innovation was derived inductively and reasonably, as the first two innovations had been. However, there was less challenging of inferences and more affective communication as part of the communication process. A portion of the conversation about the proposal specialists possibility went thus:

CZ: OK, so we've got to get management acceptance first this time on what the problem is.

RS: Well, we know what it isn't.

WL: Very funny. Who cares what it isn't?

DD: Well, I'11 tell you what problems we have in our organization are caused by. 'It's the people doing the proposals don't know anything about proposals. Engineers hate to write. I know; I am one.

BD: But proposals are writing. And look who does it--engineers. That's why we're always 
getting these gold-plated solutions that nobody wants. Engineers do it. They design the hell out of the thing, but a proposal has to sell it. But they don't want to sell it; they just want to design it as fancy as they can.

The characteristics of this group's communication began to change at this point. Up until the rejection, this mild bantering didn't occur. The affective terms, "engineers hate to write," and "gold-plated solution nobody wants," were a new kind of communication for the Defcon collateral organization. If this communication had occurred a couple of weeks before, one of the other collateral organization members would have dismissed it as a waste of time. "We know what it isn't," is a rueful expression of acknowledgement that the first innovation was a good answer to the proposal problems, as well as a reminder of their rejection. It is also one of many jibes at Mr. Johnson.

Another example of the cohesive character of the innovation communication after the collateral organization's first rejection is the members' regular discussion of the possibility of the demise of the whole organization itself:

TC: Well, I'm batting a thousand if this bombs. 
I've never been on a committee that was worth [expletive deleted].

BD: We've thought of everything this time around. If Johnson's gut tells him "no" again, though, I'm through.

WS: We're all through. If they don't dissolve us, I'm gonna do it.

Their communication is still marked by pessimism, apprehension, caution, and a discomfort with not knowing what ground they're standing on. The collateral organization group members were chosen because of their past history of getting things done, and having their first innovation rejected out of hand had been a blow to their perceptions of themselves as doers. Their former positive views of themselves had been at least temporarily replaced by a negative view of the group as a whole, based both on uncertainty in their new organization and the unexpected blow of their first rejection. All these negative factors caused them to draw together as a group. This new inward focus accounts for the change in the communication of the collateral organization noted during this stage. At this crucial juncture, they needed success. To achieve this success, they needed new and effective leadership, to lead them back to a more positive view 
of themselves and their capabilities. At this point, Mr. Siddoway overtly displayed his leadership over this group at this time, firmly declaring, "I'm gonna do it." The rejection apparently had created a context permitting the emergence of a new leader. Mr. Siddoway's leadership potential was characterized by a certain amount of ruthlessness and daring, best typified by his description of himself as a "bandit."

It is very unlikely that the collateral organization would have stayed together for six months and produced their many successful innovations had their communication remained at the strictly rational, uncertain, cognitive, and polite level it displayed before the rejection. Already attrition had set in, with five members dropping out due to "getting too behind in their regular jobs." If the group's response to their first rejection had been to continue the lack of the affective dimension missing from their interaction up to that point, they would have disbanded. Sheperd (1964) makes this point in his discussion of four group traits necessary for group survival. He states that one of the four major problems with which a group must cope is "the expression and management of feelings of the members (for example, expressing dissatisfaction or pleasure, resolving personal 
antagonisms, or relieving tensions)" (p. 28).

Many small group researchers have discovered that failure to cope with the expression and management of feelings in a group will lead to dissolution (Bales, 1950). Farace, Monge, and Russell (1976) state that managing emotions is a major problem for most groups, and critical for their very survival (p. 169).

In their healthy response to rejection, the collateral organization members ensured not only the health of the group, but its very survival. This viewpoint is also supported by clarkson and siddoway in their accounts of this intensely emotional communication:

TC: It was actually a good thing when the c.o. went crazy. That's why I didn't say anything. I thought to myself, "Well, it's about time, guys."

WS: I was glad too. You've heard that saying that if you don't have an enemy, invent one? I mark that meeting when we invented Johnson as the enemy as the real start of the c.o. as a team.

In responding to rejection by focusing on their own emotions and on Johnson as the bad guy, the collateral organization found a shared reality they had previously 
lacked. They also found a confident communicative voice, which they had not found before.

5. The effectiveness of the "staging" communication of the collateral organization was more dependent on the situation than on the thoroughness of preparation. Two briefings were held in conjunction with the first pair of innovations. The first briefing was given by $\mathrm{Mr}$. Clarkson and Mr. Siddoway to Mr. Johnson, and the second was given by Mr. Siddoway with the full presence and support of the collateral organization, to upper level management decision-makers. This second briefing was also attended by the CEO of the west coast Defcon facility.

Although the first briefing was short and less formal than the second, it was actually a better briefing. In the first briefing, some of the enthusiasm and belief that siddoway and clarkson felt toward their two innovations was evident:

TC: We are excited about this centralized marketing idea, because everyone we've talked to both in and out of the company thinks it's a great idea. We have also run a formal analysis of all the data on the issue, and it comes out overwhelmingly on top. 
Unfortunately, the value of the enthusiasm, and of the innovation itself, was lost on anyone but this author, for it was very clear that Mr. Johnson was actually enraged at the centralized marketing idea. The two presenters had spent several evenings together after work preparing this joint effort. They had made sure that every reasonable question had a reasonable answer, and thought of every short- and long-range benefit of this centralized marketing innovation for Defcon. However, they didn't have the chance to use all their very thorough preparation, for as soon as the centralized marketing innovation was clearly defined, Mr. Johnson interrupted the two presenters, exclaiming, "Where did you get this idea?"

clarkson answered, saying, "It's the result of our first product--a decision making tool. It was thought that the collateral organization should use the tool to address our marketing problems."

The phrase "marketing problems" seemed to send Mr. Johnson over the edge, for he replied testily: "Who said we have marketing problems? Where did you get the idea marketing is responsible for our proposal mess?" Siddoway and clarkson, nonplussed, looked at each other, at which Mr. Johnson concluded this very brief briefing: "My gut feel tells me that this isn't 
something that needs to be looked at. Thank you for coming in this afternoon."

Two factors bear comment from this briefing. First, the tentative nature of the presenters even in this pre-rejection stage was evident. For instance, clarkson says, "It was thought that," instead of a more direct approach, such as "We decided." Second, Johnson did not challenge the data for the centralized marketing idea. He couldn't challenge the data, because he refused even to hear it.

All the very thorough preparation in terms of the content of the first briefing was actually re-doubled for the second briefing; the unveiling of the proposal specialists group. However, no effort was put forth on the manner of the presentation. Instead, since the presenters were suffering from the aftermath of the first briefing from three weeks before, they were very deferential, respectful, and somewhat tentative in the second briefing, as they had been in the first:

WS: We are here today to brief management on the first two ideas that we believe have enough evidence behind them to warrant your attention. These are the decision making tool and the proposal specialists group. We are aware that non-technical specialists is a new 
concept for us as a company, but we ask you to bear with us and at least hear us out.

The second briefing was marked by the nervousness that the collateral organization felt especially keenly after being rejected by Mr. Johnson. Although they were very thoroughly prepared, and had thought of every contingency, there was no enthusiasm for this project. Note the language used in these two passages, always marked with qualifiers and apologies:

TC: We are confident that the proposal specialists idea has the best evidence to support it; at least it's the best of the options we examined.

WS: We are sorry that we can't show you the entire ranking of evidence that went in to the tool for this particular run.

The characteristics of the communication from the collateral organization members are similar to those of the meetings. They are at every turn reasonable, serious, cautious, and devoid of affective responses or displays. The organization's lack of confidence was also betrayed in the presenters' tentative language and nervous gestures. They both hesitated, qualified, apologized :

WS: We think that you will probably agree that problems have been apparent in our proposal 
process. Of course, this is not to point the finger at anyone.

TC: We know that we are all determined to fix these problems, aren't we?

WS: I am not sure what management wants to do about this issue. I am sorry we haven't had the time to research that more carefully.

TC: Well - . - That's difficult to say. Perhaps we could, well, no, we had better. . . I'll make sure that it is discussed at our next meeting.

Not only was the language guarded and tentative, but the presentation manner betrayed the same lack of confidence. For instance, at the second briefing Siddoway stopped after each major point, as if waiting to be interrupted or cut off completely, as had happened the first time with Mr. Johnson.

Despite the fact that the communication in the second briefing was inferior to that in the first, the recommendations in the second briefing were accepted, whereas those in the first had been rejected. It appears that the total situation inherent in the briefing is more relevant to the outcome of the briefing than is the quality of the communication taken by itself. Communication is one factor in a shared 
reality, but it is not necessarily the overriding one. In this case, a weak briefing of the proposal specialists idea achieved the results that a well prepared but undelivered briefing of the centralized marketing idea failed to generate.

The pattern of a later briefing being less prepared but better received also took place on some of the collateral organization's later briefings. In these later examples, the legitimacy generated by the collateral organization's successes seems to be more important than the communication itself.

For example, late in the year two briefings were held by the collateral organization to bring upper management up to date on the latest results and innovations. One of these briefings was to push the library prototype, and the other was to present the new proposal facilities innovation. The library prototype briefing was a huge meeting, with all of upper management present, including the Defcon CEO and the corporate-wide CEO, Mr. Delima. In the informal communication at Defcon, the label "Godfather" is used with respect to Mr. Delima. Famous for his volatility, he never sits still in meetings. He seems to inspire fear. This awesome reputation was discussed at length in a collateral organization meeting preceding the 
briefing. Yet siddoway and the others did not tirelessly prepare a faultless presentation. For an infinitely easier audience they had been exceedingly over-prepared. However, this was not the approach in this later stage of the collateral organization's history. Delima's visit and attendance at the briefing brought forth a rehash of old rumors, but no special preparations were made for this briefing. This meeting took place on November 15, 1988, and communicatively was of no special significance until Delima interrupted Siddoway's speech. He had been pacing at the back of the room during siddoway's presentation of the prototype and actual libraries. Suddenly, Delima stopped, and from the back of the room began shouting, "This is - Total ! " He then slammed out of the room.

There was a second or two of stunned silence, while the audience avoided looking at siddoway. Into this void came the voice of siddoway, announcing in an indulgent way: "Geez, he really went ballistics, didn't he?"

The audience howled with laughter, after which siddoway concluded his briefing. This casual comment of Siddoway's was an astounding move, if one considers both who Mr. De Lima is, and the fact that siddoway was 
in the meeting to receive approval for a very expensive innovation.

The full library, at a cost of $\$ 5,000,000.00$, was approved as the result of this briefing. That it was approved on the spot may indicate the library was pre-approved at some other time. Or, it may have been as a result of Delima's outburst and the subsequent tension-releasing comment of siddoway's. Finally, Siddoway's prior work on the corporate-wide committee may also have played a role in the success of this innovation. Whatever the reasons were, they were not disclosed. Some of the decisions about collateral organization innovations took place in meetings closed to this author. The important point for this study is that once again, the total context, unknown though it may be, still obviously overrode the fact that the briefing was not fully prepared and that Delima so firmly rejected it. Once again, the preconditions and context shaping the situation appear more potent than pure message quality, good or bad. The very assured characteristics palpable in both the words and manner of Mr. Siddoway were evidenced in both his lack of preparation, and his quick comment about DeLima's behavior.

This briefing was also important for what was 
missing: no handouts, bound reports, or other presentation materials that had been so carefully prepared in the phase one briefings could be found at this briefing. And that was done with full knowledge of the audience for this meeting. The only visible prepration was a flip chart that siddoway used during his presentation.

The last briefing held to present the sixth innovation of the collateral organization was the most striking example yet of how far the group had come since its first shaky, nervous briefing of Mr. Johnson. This briefing was, like the previous one, held for all of the upper management at Defcon. Again, the local CEO was present.

However, this briefing was not presented by a member of the collateral organization, but by an architect. The architect had drawn up the plans for the proposal development facilities. These facilities had, again, already been budgeted for and approved. This briefing was merely a formality. At the conclusion of the architect's presentation, the local CEO rose and delivered a short eulogy of both $\mathrm{Mr}$. Johnson and Mr. Siddoway. He praised them both for "their vision, their incredible ability to foresee the future needs of Defcon, and their loyalty to Defcon and 
all it stands for."

In business communication textbooks, thoroughness of preparation is the advice given for every formal presentation of ideas to management. There is assumed to be a cause/effect relationship between assured, thorough preparation and presentation and desired outcome. However, these briefings made by collateral organization members to management seem to dispel that notion. The outcome is much more dependent on outside factors, predispositions, and politics than on the actual communicative event of the briefing. This is further evidence that the reality of the situation is far more potent than the message, which is really just one element of the situation. Another way to look at it is that the effective communicator will become totally familiar with that reality (i.e., make it a shared reality), before communicating. Time spent understanding the situation is far more valuable than time spent polishing the mechanics of the presentation. This general point is made by Bitzer (1970), who identifies three crucial elements for the presenter to consider: exigence, audience, and constraints. This is not to say that the mechanics are unimportant or not worth working on, but merely to insist that mere mechanics cannot substitute for accurately 
understanding the situation.

6. The written communication of the collateral organization was selectively disclosed and tailored for an audience.

The written documents used for this analysis consist of collateral organization meeting minutes, reports, and memos from May 31, 1988, until the acceptance of the proposal specialists group in September of the same year. In addition, memos written to the collateral organization members from $\mathrm{Mr}$. Johnson, to whom they reported, are analyzed during the six months the collateral organization existed. Part of the original memo sent throughout Defcon announcing the formation and membership of the collateral organization is reproduced below:

A special temporary organization has been establishea to study and recommend solutions to enhance our current method of proposal planning and preparation. . . I believe great value will be obtained from this effort. We are fortunate to have the experience and capability of [TC] directing this effort and I solicit your support to help him generate a good product. (J. Johnson, personal communication, May 31, 1988) 
Mr. Johnson followed this with a memo to each collateral organization member:

Every aspect of the current way we do proposals is open to scrutiny. There are no preconceived notions about what the problems are or where they reside. - . This group is given no preconceived notions about what is or is not a potential solution. (J. Johnson, personal communication, June 7,1988 )

Both of these communications are actually very misleading. The first memo with its formal and congratulatory tone makes two statements that turned out not to be true. First, Johnson never told clarkson he was to lead the group. Thus, although clarkson did take the lead in the beginning of the collateral organization process, his only inkling of this plan was from this memo. Secondly, as will be evident from accounts described later, Johnson had no intention of soliciting company-wide support for the collateral organization's efforts. He planned to keep a close eye on their efforts, evaluate solutions himself, and implement those that were beneficial to his arsa of the organization. This will be shown below in a discussion of the account given by Johnson in a follow-up interview. 
The second memo promises more than Johnson was willing to deliver. Again, the "preconceived notions" of Mr. Johnson were responsible for the rejection of the first innovation. At this early stage of the process, the formal written communication channel seemed to serve a nominal announcement function that left out the important variables. Also, the preconceived notions proved far more powerful than any argument, at least in terms of what happened for the centralized marketing innovation.

The first formal memo written by Mr. Clarkson to Mr. Johnson reveals an ambiguous and "leave out the essentials" approach to communication:

I would like to take this brief opportunity to express my personal thanks to you for putting me on the proposal study organization. I have long been concerned about this aspect of our business, which is one of the few where I think we have serious problems. I know the problems facing us in this area are serious and difficult and I appreciate your confidence in me. (T. Clarkson, personal communication, June 9, 1988)

A memo written by siddoway after the rejection of the centralized marketing innovation was similarly formal, respectful, and selectively disclosed: 
Most members of the group are now in full agreement with me that the centralized marketing idea would not be consistent with our particular structure and our particular and delicate customer relations. I am confident that we are now working in positive directions sure to be synergistic with the existing company policies, procedures, and past practices. You may look forward to receiving some unique and implementable ideas in the near future. ( $w$. Siddoway, personal communication, August 10, 1988) siddoway accomplishes two things in this memo. At the start, he utilizes an identification strategy, appealing to "members of the group" who are "now in full agreement." This serves to draw all the readers together as members of the Defcon team. This identification includes Johnson himself, whom Siddoway is parroting in the memo (unknown to the other readers). Thus, siddoway is writing for two separate but related audiences in this memo.

Second, words and phrases such as "full agreement," "delicate customer relations," "confident," "positive," "synergistic," "look forward," and finally "unique and implementable ideas," are loaded with an optimism and respect that are not in accord with Mr. Siddoway's behavior in the post-rejection meeting or his later 
account of his feelings at this time.

Unfortunately for all of Siddoway's sunny optimism, his memo crossed in the mail with Mr. Johnson's memo to the collateral organization, that formally revoked the broad charter. This memo was received by the group after both their post-rejection meeting and their first conception of the proposal specialists innovation, making its impact anti-climactic:

- . as with any broad charter, there is a risk of extending inquiries and analysis into areas that won't bear fruit. After the recent status report you gave me I want to place some constraints on the future work . . . The remainder of the Collateral Organization's efforts should concentrate on procedural, organizational, training, and methodology issues to enhance our proposal planning and preparation process. (J. Johnson, personal commritustion, August 9, 1988)

Although informally a rebuke, it still left the actual areas that were fruitful for consideration by the group very broad. It is also revealing for what it leaves out: it never discloses why the centralized marketing idea was anathema to $\mathrm{Mr}$. Johnson.

Although few memos exist from this early period, their characteristics are consistent. They are formal, 
respectful, general to the point of vagueness, and very selective. They say very little, actually, but they serve as a substitute for communication that would be much more of a strain. For example, in order to avoid a controversy about choosing a leader of the collateral organization, Johnson simply inserted his preference into a memo, thus avoiding having to face questions about why a junior technical specialist would be chosen over more senior-level managers.

Also, rather than specify exactly what he wanted the group to study, he gave them a "broad charter." This broad charter was very strategic, as disclosed to the author after the collateral organization had disbanded. Johnson had decided ahead of time that if the group came up with a plan he didn't like, he could reject it out of hand. If they came up with something he liked, perhaps it would be a truly innovative answer, and he could claim that his free rein had provided creativity within boundaries. In his memo revoking the group's "broad charter," he avoided an explanation for his rejection of the centralized marketing innovation. He did not mention the decision making tool, thus consigning it to a sort of limbo. Then, in his narrowing of the charter, he gave a general list of problems, that could be interpreted 
in many ways. Again, the result was to give the group freedom. While the intent of the memo seemed to be to chastise them for "wandering into unfruitful areas," he never came right out and rebuked them.

These memos seem to be an artful and delicate communication that reveals a between-the-lines message that can be denied later if events require it. Siddoway's memo to $\mathrm{Mr}$. Johnson is also artfully disclosed. This communication might be too positive given the treatment he received at the briefing. However, this is open to the interpretation of the receiver, as is intended.

The minutes from the collateral organization meetings are also full of selective disclosure. They were brief, with the actual decisions being considered and the conclusions reached very selectively disclosed. For example, the first minutes of the collateral organization meetings simply have the dates, members present, and action items appearing in a brief list. As the technical specialists began work on the decision making tool, however, the action list fails to mention this fact. As a result, the minutes of the first six collateral organization meetings essentially look like those preceding and following, with dates changed. However, as watered down and non-specific as the 
meeting minutes are, some of the same qualities that characterized the oral communication at the meetings can be identified in the "sterile" minutes:

We need to be prepared next week to present ways that we can increase speed and efficiency. . . (C.0. meeting minutes, June 13, 1988)

Drivers of proposals identified as:

1. early start

2. quality

3. efficiency

4. responsiveness

5. reviewability

6. win strategy

(c.0. meeting minutes, June 27,1988 )

What these minutes fail to document, however, is exactly what is being done about these "proposal drivers." Since Mr. Johnson was receiving a copy of the minutes each week, perhaps the group was saving the actual product so as not to pre-empt themselves.

Without duplicating each set of minutes here, suffice it to say that all the minutes generated were less than two pages long, with communication that was broad, vague, and left out the key innovations being worked on. However, the most minute details are included, such as, "Diane get a flip chart," "look for 
a larger room," "see if Tom wants to visit a c. 0 . meeting," "get help on data flow diagram," "talk about changing meeting times," and "get better copies made of problem document."

These details are not included in the author's field notes, but appear to be key action items in the minutes. In other words, the minutes do not reflect, and in fact may purposely hide, what was really going on in the collateral organization at this early stage. Many possible reasons account for this selective disclosure. First of all, the organization as a whole did feel that it was facing a hostile and uncertain world, which may have fostered a tendency to be cautious about what was stated, especially in writing. second, the organization itself had not yet achieved an identity or shared reality, so possibly it was difficult for anyone to feel comfortable writing in a firm voice for a group that had not yet discovered its own voice.

Later on, after the collateral organization was well established, the pattern of selective disclosure continued. In these later cases it seems likely that selective disclosure was practiced as a "bandit" device, through which members of the collateral organization could manipulate the reality of other 
groups within Defcon whom they were trying to influence.

For instance, the selective nature of written documentation continued to be the case once the collateral organization was permanently embodied in the Proposal Support Group. Mr. Siddoway in his function as head of the PSG began to send memos that dealt with criticism of his group, a delicate subject requiring careful manipulation of reality and highly selective disclosure:

Recently, various persons in the Proposal center and the Chief Engineer's office have voiced concerns that the new Proposal support Group may be overstepping its charter in its development of a Proposal Data Base. Please be assured that the Proposal support Group has no intention of treading on anyone else's territory. . . . The fact remains that our division needs a proposal data base and no one else is taking the lead in fulfilling our requirement. Therefore, we have felt it incumbent on us to to fill it for ourselves. In so doing, we have also borne the cost of this development ourselves at the division level. (W. Siddoway, personal communication, November 4, 1988) 
This official memo, stating a rebuttal to the voices of concern who felt that the PSG "might" have been "overstepping its charter," was circulated throughout Defcon. Siddoway had, in fact, been told by Mr. Johnson in a meeting that the PSG was threatening to proposal center employees, who felt that they were being left with no proposal functions to perform. Johnson had directed siddoway to write up a report detailing exact functions, goals, and job descriptions of PSG members. Johnson also let siddoway know that he wanted him to continue with the PSG. Significantly, the PSG reported to Johnson, but the proposal center did not. In other words, Johnson knew how to use Siddoway's talents and energies for his own ends. However, instead of following Mr. Johnson's directive, siddoway sent the memo above, and followed it with a memo just for Mr. Johnson:

We are attempting a completely detailed report per your instructions. This, however, cannot be fully completed until Frank [CEO] makes a decision as to PSG relationship and level within the Business Area. However, there is no hurry as far as the PSG is concerned. . - Perhaps time will tell best what the full function of the PSG will be. . . . As PSGsupported proposals continue in the winning mode, 
its relationship within the Defcon organization can be more clearly determined. ( $w$. siddoway, personal communication, November 10, 1988)

The first memo circulated to Defcon employees is reasoned and respectful. Siddoway also sounds a bit put upon: "we have also borne the cost of this development. . . ." However, like most of the written communication, this memo leaves out more than it tells. It doesn't address the very real concerns of other proposal center specialists whose job functions have been slowly been sliding into PSG hands. By this time, the PSG was involved with every major proposal effort throughout division 1 , and at other facilities. The proposal center employees' concerns are understandable, yet they were not addressed very satisfactorily in the first memo. Siddoway does assure his audience that the PSG has no "intention of treading on anyone's territory." However, this assurance is not supported with either specifics or the fulfillment of Johnson's request to delineate clearly who's doing what.

What is happening is that through selective disclosure, siddoway is presenting just the world view that he finds useful, while ignoring elements that might imply another possible view, or contradict the 
view he wishes to present. The point of view of the current proposal center employees, for instance, is discounted or ignored throughout both memos.

The memo to Johnson is, again, very formal and respectful. However, it also clearly sends the message that the specific job functions are not going to be spelled out as yet. The inference is there that the "winning mode PSG-supported proposals" will help this separation of both functions and places on the organization chart.

Again, the written innovation communication of the collateral organization at this stage serves an important role: it selectively responds to queries; it formally and ambiguously makes assurances that it then blatantly ignores; and it retains the illusion that there is two-way communication happening here. An excellent example of selective written disclosure used to manipulate reality was used by $\mathrm{Mr}$. siddoway to justify the following memo issued to the collateral organization:

From several recent meetings with [the vice Presidents of both divisions], as well as discussions with their respective proposal area leaders, I have concluded that our collateral organization's work has been very positively 
received and that in fact our input on the organizational trade-off in particular has been accepted. Specifically, it now appears that both [divisions] are actively moving forward to implement our proposed organizational model. . . This decision being the case, it renders superfluous our next scheduled report and any more work detailing and documenting a set of trades on issues that are already decided. The major issues such as marketing and the role of proposal specialists are already decided. Attached are what notes I have from both divisions indicating the directions that each is taking. (w. Siddoway, personal communication, December 12, 1988) The effect of this memo was dramatic. The next day, one of the senior members of the collateral organization came immediately to Mr. Siddoway's office to complain that this was ", , to which Mr. Siddoway readily agreed. However, he went on to explain his purposes, which were twofold.

His first purpose was to get the conclusions and successes that the collateral organization had already accomplished institutionalized and made permanent. By referring to them as already accomplished, he succeeded in this effort. 
The second purpose was to eliminate the collateral organization gracefully. Mr. Siddoway had begun by writing selectively disclosed and distancing memos to management, and ended by doing the same with his own collateral organization. As the collateral organization wound down to a close, the written communication helped this winding-down phase. It permitted some necessary distance to creep into the communication between group members, making the disbandment take place more easily. It also created some distance between the emotional bonds that had been forged during their several months of working together, especially during the emotional period of rejection.

Management had made no move to disband the collateral organization. However, all of the innovations that were deemed possible had been implemented. And, the PSG had taken over many of the functions for which the collateral organization had originally been utilized. Still, it was a surprise to the group when the Friday before the group's last regularly scheduled meeting for the year, siddoway sent them a memo that disbanded the collateral organization:

Instead of trying to solve the whole proposal problem with a "big picture" analysis and solution, 
we should now come to management with a small and specific working tool, such as another specific data base product. The hope is that with virtually no expense, we can develop a set of such small working tools and build these up into a "proposal wide" solution. It amounts to a bottoms-up approach rather than a top-down approach. It amounts to a cheap rather than an expensive solution, in line with today's reality. The collateral organization will not meet again until we have at least one small tool to demonstrate. (w, Siddoway, personal communication, Dec. 23, 1988)

The collateral organization never did meet again, because this small tool concept had already been accepted by management and the PSG was working on these "small tools."

After six months of intense interaction, with five successful innovations behind them, there was no formal or emotional leave-taking. The core members of this group had forged a group identity together, had created legends along with their innovations, and never did formally disband. The shared reality of the collateral organization was made permanent in the proposal support group. The new group was official and legitimate in 
its own right, so it did not have to go through the trauma of rejection and legimization. However, it also did not get to indulge in the "bandit" communication and activity of the collateral organization. In maturity, the collateral organization totally joined the reality of the larger organization, which now included the innovations of the collateral organization. At this point, the collateral organization was counter-productive, especially if left to continue its activities unchecked.

This selective disclosure and tailoring to an audience for manipulative purposes was discussed in an interview with Mr. Johnson and Mr. Siddoway after the group no longer formally met. The author was seeking confirmation for this phenomenon, as well as explanations for its acuteness at Defcon. Mr. Siddoway explained it thus:

WS: Every engineer at this facility hates to write memos, and I'm no exception. It's the only drawback to the security precautions: that we don't use secretaries for all this. So I only write when I'd just as soon not confront, or make a muddle of talking to someone. Actually, it's cowardly sometimes.

SL: Do you think most employees here only write 
memos for those reasons?

WS: I've never thought of it. Maybe some, to some extent. The purpose of anything is to get the job done the best way. Usually the best way isn't memos 'cause nobody reads them too much. They serve their purpose, though.

Many underlying motivations seem to be revealed here: "engineers hate to write" is one that had been voiced before in collateral organization meetings. Not wanting to confront, making a muddle out of face-to-face communication, nobody much reading memos, and that they serve "their purpose" (as long as people read what you want into them), all support the notion of selective disclosure for manipulative purposes.

The other accounts gathered on this topic also reinforce the author's finding on selectively dislosed written communication:

SL: Do you recognize any of these types of communication?

ws: Definitely. In fact, I still use memos for the b.s. stuff.

JJ: I wouldn't characterize memos as b.s. I don't ever remember saying something in a memo that was an out-and-out lie. 
I do, though, tell maybe a tenth to a third of the whole story. That's all anyone needs to know. "CYA" is no joke these days, with all the people who wrote down inadvisable things and then couldn't round it back up fast enough afterward. Siddoway openly calls the memos he writes as serving the function of the "b.s. stuff." Mr. Johnson is less ready to name it thus, but does add an enlightening dimension to the sparse and selectively disclosed written communication, which he estimates is "a tenth to a third of the whole story." He also reminds us that having to cover oneself has been demonstrated to be important. The "people who wrote down inadvisable things" were very much in the news at this time. Their "not being able to round it up fast enough" refers to the well-publicized trips to the shredder to which much of this written communication was fated. Mr. Johnson and others at Defcon identified with some of the problems that counterparts in Washington were having with their inability to "cover themselves" either quickly or thorouqhiy.

The need to cover oneself referred to by $\mathrm{Mr}$. Johnson is not limited to "these days." The importance of communication that is "deniable" has been identified 
previously. Labov and Fanshel (1977) make the claim that humans have a great need to have some communication, usually written, that fulfills the function of deniability. They go a step further by stating that if we didn't have this form of discourse that fulfilled a deniability function, we (humans) would invent one. Undoubtedly, defense contractors and government employees in security-conscious jobs feel the need especially strongly to be able to deny activities or communications. However, it might be that Watergate with its audiotaped communication, and Irangate with its shredded and unshredded memos have made employees in many types of organizations very aware of the necessity of deniable communication.

7. The formal communication of the collateral organization was incrementally disclosed and ambiguous.

Accounts were solicited from key players as a means of gathering reflexive commentary on their underlying motivation and justification of events that had been unexplained both to the author and other group members. In addition, gathering accounts was intended to fulfill Deetz's (1982) admonition that a researcher undertaking an interpretive study in an organization seek to make 
the text maximally reasonable and coherent as well as striving for the greatest degree of familiarity with the data (p. 144).

In order to best understand the collateral organization from a phenomenological viewpoint, these accounts not only serve to tell us what individuals' actions "mean," but they can, by describing how actors themselves communicate these actions, shed light on relevant norms and values of the organization.

The author anticipated that these accounts would simply serve a reinforcing or confirming function in the research. However, the formal communication that was required by the formal interview situation produced its own category of innovation communication. The interviews followed a pattern of incremental disclosure that was similar to the phenomenon of strategic ambiguity identified by Eisenberg (1984). He states that strategic ambiguity is organizationally essential in that it: "1) promotes unified diversity, 2) facilitates organizational change, and 3) amplifies existing source attributions and preserves privileged positions" (p. 227). This strategic ambiguity differs from the selective disclosure described in the discussion of the sixth proposition in that selective disclosure implies a purposeful withholding of 
information, while strategic ambiguity does not. A communication exemplifying strategic ambiguity may nonetheless contain all of the facts, while a selectively disclosed communication hides many of the facts.

In the accounts produced in the formal interview setting, strategic ambiguity was evident in an incremental fashion. Rarely did an interviewee simply blurt out his or her motivation or justification. With probes for amplification, an incremental tale was unfolded line upon line. However, still more rarely did "the whole story" emerge. Rather, what emerged was the interviewee's or actor's version as to how they wanted the accepted scenario to be framed.

The first accounts were solicited from Mr. Johnson in an interview shortly after the formation of the collateral organization. Because no rationale had been given either formally or informally as to the criteria he had used for selection of these members, the goal of this interview was to understand $\mathrm{Mr}$. Johnson's motivation:

SL: How did you decide who was to be on the collateral organization?

JJ: Well, first off, I was looking for folks who came from different parts of the company. 
SL: Did you plan that wide-ranging membership of the collateral organization with any particular goal in mind?

JJ: Yes. I wanted to get maximum representation from the entire sector, because that's supposed to be what works in a collateral organization and because I felt that they could sell new ideas back to their specific areas of the company.

SL: How?

JJ: I knew that if I picked the right people, they would have more influence with their own managements than I could.

SL: That explains the diversity, but not the individuals themselves. Was there some profile, or set of criteria used to analyze people's capabilities?

JJ: Like what? Who's good at creative stuff, who's a team player, who gets along with whom?

SL: Basically that's what I mean. Sort of a mental resume.

JJ: Do you want to hear the company line or the real reason?

SL: How about both?

JJ: OK. Company line. I expected that various 
elements of the sector would contribute to the solving of the proposal problems. I expected that their contributions would be more forthcoming if they had the feeling that their own people had had an influence on the exact shape of the solutions.

SL: Why did that require a collateral organization?

JJ: Because the problems are too big for any one element in the sector or the division to fix by itself. The breadth of the problems demands a similar breadth of resources and therefore some coordination among that wide range of resources. That coordination is provided by the collateral organization.

SL: So officially, the membership of the collateral organization was selected to represent all the various necessary resources?

JJ: Yes. But now for the real reason. Not just to represent the area, but because of particular connections within that area. At the risk of sounding like a manipulative s.o.b., everyone was chosen because they were outstanding in their area and they had friends or some sort of connections. For instance, 
Manny Fierro is not just from the engineering directorate; he is on their technical library staff and so he has direct access to old proposals and other historical documents that I think will prove useful to the solving of the problems. Siddoway was chosen because he is new, ambitious, and doesn't care who he steps on. And he won't take no for an answer. clarkson is the best engineer and probably the most respected. Those are typical examples of why I went after a specific person to be on the collateral organization. In most cases, I felt that the individual has a particular connection with our proposal process and also with our proposal problems. I hope that means they will be able to offer a particular insight into the solutions.

SL: So the official reasons are organizational, but the real reasons are personal.

JJ: Exactly. People make the real things happen, not organizations.

Mr. Johnson prides himself on keeping current with the OD literature, being the first to actively recruit minorities and women, and being a real innovator himself. He also seems to be a power broker who 
privately chose each member of the collateral organization. His statements make clear that he is sometimes manipulative and even misleading with some of his language. In the foregoing accounts he assumes an "aw-shucks" persona, but keeps the account in line with the idea that collateral organizations have wideranging representation. He also reiterates the "different parts of the company" rationale, but adds a new dimension: collateral organization members "could sell new ideas back to their areas." This reveals a somewhat new angle on the membership, which is that he needed influential members.

The second set of accounts in this sequence is what Johnson dubs the "company line." The company line, as revealed by Johnson, is that problem-solving would be facilitated by wide-ranging membership. But later in the interview Johnson names "the real reason," which actually consists of two angles: connections of each group member, and personality traits that would contribute to success of the organization. His final comment that "people make the real things happen, not organizations," shows his bottom-line: he chose people who would make things happen. Finally, because he formed the collateral organization, and had them report to him and no one else, he not only shared in this 
power but could take credit for success.

Communicatively, he slowly revealed aspects of his motivation as the interview progressed. His series of accounts was not a thorough and reasoned statement of events, but rather a calculated series of timed and selective disclosures. Thus, Mr. Johnson's accounts are themselves a good indicator of how he goes about communicative tasks. Mr. Johnson had apparently carefully assessed potential members' personal characteristics, expertise, and strategic placement and ties within the larger organization. Thus, he put together a group that would most predictably lead to successful problem-solving. He also manipulated the entire operation to be of maximum benefit and mimimum cost to his own organization.

The following accounts were also provided by $\mathrm{Mr}$. Johnson in order to uncover his motivation and justification for rejecting the collateral organization's innovations. When this account was gathered, the rationale for the rejection had not been disclosed either formally or informally, so it was still a source of mystery for the group members:

SL: Why did you decide against the centralized marketing organization?

JJ: our business just isn't structured for a 
centralized solution. We're a matrixed organization.

SL: But didn't the collateral organization use the automated decision making tool, which took that into account?

JJ: I suppose they did, but the tool is only as good as the data it gets.

SL: Don't you have confidence in the tool itself?

JJ: I guess I don't. If the tool had good data, it wouldn't have come up with the wrong answer.

SL: But how do you know what the right answer is?

JJ: I guess it's my $30+$ years of work in this business. It's my gut feel, based on that experience, that centralized marketing won't work.

SL: So why did you let the collateral organization consider that possibility?

JJ: Actually, the breadth of the charter was a mistake on my part.

SL: Can you explain any more objectively?

JJ: You don't like my gut feel and 30 years of experience?

SL: No. I just thought there might be some other reasons too.

JJ: Well, yes, as a matter of fact there are. 
From an organizational point of view, I didn't want to allow the marketing function to get out of the business area control.

In this series of accounts, the familiar "stated reason" and "real reason" dichotomy is revealed, indicating the ambiguity and incremental disclosure typical of Johnson. After giving several stated reasons, Johnson finally hints at what was probably the real reason for the innovation's rejection: organizational structure. But then he backtracks some. In this account, Johnson reverts to his "gut feel and $30+$ years" rationale. He elaborates by referring to the "level of experience," of which he has most. Throughout this dialogue, he is consistently vague and indirect: breadth of charter was his mistake; it's counter-productive for them to work on a losing proposition, etc. This stays with the same generalities that seem organizationally sound, but reveal little. Thus far the properties associated with these accounts are distinctly vague, indirect, and broad, like most of the communication from this early period.

The last portion of this account finally reveals his motivation. The marketing function at Defcon is under the control of the business area, of which 
Johnson is the head. Mr. Johnson wants to retain control of this function; therefore he does not want to create an external or centralized marketing group.

The other two accounts solicited from early in the innovation process come from the two key players, Clarkson and Siddoway. Both of these men were or had been collateral organization leaders, they were both highly involved in the creation of the innovations, and they had been the two presenters at the briefing where the rejection had taken place. A question was asked of both of them as to their thoughts and feelings about the way Mr. Johnson had handled the briefing in which the centralized marketing function was rejected.

Siddoway's account of his reaction reveals only a portion of his thoughts about being summarily rejected:

WS: I was surprised. I guess that I was so confident that the centralized marketing idea was a good one that it never occurred to me that anyone else could possibly disagree. I mean, Johnson especially, since he had called for the group and given it such broad power, as I thought. But the worst thing was that I knew I would have to work 
with Johnson every day, in my regular

job--since I report to him--and I guess I just felt embarrassed that he had publicly disagreed with me.

clarkson's account reveals a more philosophical and reasoned attitude toward the rejection than siddoway's:

TC: Maybe it wasn't so surprising. Well, I don't work with Johnson on a regular basis anyway, so now that I know him a little better, I'm not surprised. He's pretty conservative and careful, which

I guess he's supposed to be in his position. That's his job, to keep the young turks from wrecking the company. We present ideas and he decides. That's why he makes so much money.

A week later, the author asked siddoway whether he was still discouraged, and he replied, "I guess I'd better go see a headhunter. I can't survive in an environment where I'm not allowed to do $m y$ job. I left the government for just these reasons and I'm not going to start putting up with it now." Johnson chose siddoway partly because "he wouldn't take no for an answer"; he is apparently a good judge of character. Siddoway at first reveals that he was surprised and 
embarrassed, but then a week later discloses that he's thinking of quitting because of his frustration. Clarkson is philosophical, projecting on to Mr. Johnson a conservative and careful characterization that is probably far from the mark.

The account solicited from Mr. Siddoway during the waiting period after the second briefing, before the proposal specialists idea had been accepted by management, sheds light on two elements that were to underlie the next phase of the collateral organization:

SL: Why were you so nervous about this briefing? You were obviously well-prepared.

WS: I was nervous because I was burned up over the way I was treated the first time around. I knew we were through if it happened again. I also knew good and well that this proposal specialists idea's not half as good as the centralized marketing idea. So the chance of it blowing up was bigger this time around.

SL: Are you still, as you say, "burned up?"

WS: Nope. I've decided we're actualiy in a no-lose situation. We've got absolutely nothing to lose at this point.

First, we have a new explanation from siddoway in which he admits that he was truly angry over the 


\section{PLEASE NOTE:}

Page(s) not included with original material and unavailable from author or university. Filmed as received. 
accounts, the researcher can see the organization as its own members see it. Without these data, the view of the collateral organization would be much less complete, showing only the public face of the shared reality of the organization, but not the inner shared reality, which always accompanies it.

8. The success of the collateral organization was reflected in celebratory communication which reshaped the shared reality of the larger organization. Enthusiasm ran high at the first meeting following the Defcon-wide announcement of a proposal specialists group. The conversation at the meeting reveals none of the caution and tentative rationality that marked the first three months of meetings of this group. The group was much smaller than it had been at the beginning. There was thus a sort of winnowing process at this time, in which less dedicated members of the group fell by the wayside.

The defection of the one female member left the "secretarial" position unfilled. No other member could be coerced into taking notes and writing up minutes, so Siddoway decided that they should dispense with notes and minutes. He pointed out that since the author was taking notes, if clarification were needed, this 
participant observation would come in handy. This request, along with a request for the author to sit up at the conference table with the group rather than behind them, was indicative of a trend toward informality that was to mark the group communication process during this phase. The shared reality within the group was new, the communicative norms were also new, and both were indicative of a new and unusual way of doing things that held sway only in the collateral organization.

This portion of discussion from a collateral organization meeting immediately after the acceptance of the proposal specialists idea is representative of the new directions that the innovation communication took in this group:

BD: I feel like we oughta hand out cigars or something, you know?

WS: Hold that thought and save those cigars. We've got a foot in the door, and so we've gotta keep it open. Clarkson, what's the story on that Heinz 57 paper?

TC: The pickle papers?

DD: I don't get it.

TC: The problem document, remember? We had 57 problems on it? Heinz 57 pickles? (Laughter) 
WS: I think that was a good tool. Just because it came up with a solution that the clown dian't like doesn't mean it's not a damned fine piece of work. Let's use it to apply to our next innovation, which, by the way, folks, we'd better move on pronto.

DD: Who's hiring the proposal specialists?

WS: Moi.

DD: You got a job for my mom?

ws: Not if she looks anything like you, buddy.

LB: Are they gonna be on the c.o.?

ws: No, no! No! This is just for the elite, the team.

This celebratory communication was understandable after the amount of work and rejection that this group had been involved in. However, this playful, irreverent bantering interspersed with a few task items became the common communication mode. The problem document thereafter always was called the pickle papers. In fact, members throughout the Defcon organization still call this document the pickle papers. Mr. Johnson, who is a short man with the misfortune of having size 13 feet, was "the clown" for a time until it changed to the "Reagan lookalike winner," because he has a Reagan pompadour, to "deep 
pockets" because he started coming up with money for their projects. Assigning nicknames became the unofficial task of the collateral organization, third phase. These nicknames were almost always indicative of the collateral organization's status of being "above the laws" that applied to normal groups elsewhere in Defcon, who until then didn't have the luxury of calling a senior manager "deep pockets" or a major report "the pickle papers."

This shared reality is not unusual. Most organizations in silicon valley use standard security phrases. "For your information only," "need to know," and "Defcon sensitive," are all examples. The collateral organization began to put these phrases on inappropriate documents, which in fact were not sensitive or in the "need to know" category. Every piece of scratch paper was furiously stamped with confidential and other sensitive material stamps. One of the collateral organization members had a huge stamp made that read: "Collateral organization Top secret Ultra Sensitive: Only the Blind May Read." This stamp was then used on any piece of paper in sight. The group members also isolated themselves communicatively from the other members of the organization. This was accomplished through constant references to the "team," 
and finally, cups, stationery, and stickers that proclaimed: "I'm on The C.O. Team." They were on an elite, very successful team that was beginning to take on some legendary qualities. Stories, exaggerations of the group's machinations, and their nicknames for management were circulated and re-circulated. This sounds excessive, but in fact, is parallel to the activities that occur when a proposal wins at Defcon. The proposal name is emblazoned on cups, pencils, paper, and stickers. A person who has attained real status and credibility has been able to collect a roomful of these artifacts. The fact that the collateral organization had made itself permanent in this manner indicates what a high degree of security the members felt with their very high credibility and status. When the Proposal Support Group was formed, this artifactual process was repeated with PSG stamped everywhere. In the Proposal Support Group, a shared view of reality was institutionalized.

Selznick (1948) has described the propensity of organizations for creating adaptive mechanisms that manipulate formal processes and goals. He also makes the claim that these deviations from the formal system can contribute to rather than hinder objectives in an organization (p. 27) . The innovation communication of 
the third phase in the collateral organization was most decidedly an adaptive mechanism that manipulated formal processes and goals. It was also at all times playful and irreverent.

This playfulness became ritualized, both orally and artifactually. The nicknames, humorous references to the centralized marketing failure, words from foreign languages ("moi," "pronto," "ah so"), sly references to upper management, and teasing one another became a norm. Pacanowsky and O'Donnell-Trujillo (1982) explain that "participation in such events provides access for members to a particular shared sense of reality" (p. 126). Because this group had shared three months of uncertainty, this playfulness undoubtedly helped shape their new role as "bandits" and "the team." Abrahams (1977) states that self-created rituals "have a sense of wholeness and potential to them; they invoke special ways of acting, special language, rules, and even boundaries" ( $p .100$ ).

Roy's classic (1960) "Banana Time," depicts grown men who have ritualized play so that the boredom of their very routine jobs will be bearable. This is similar to the sentiments expressed by $\mathrm{Mr}$. Siddoway in the last interview the author had with him at Defcon. He reminisced about the "crazy" times the collateral 
organization had together, and summed up his feelings about the process: "I looked forward to getting up in the morning. Instead of a dull routine that was pathetically predictable, we got to play cops and robbers. And get paid for it."

The boundaries were stretched by the collateral organization when the members ordered the paraphernelia that was only given out in a formal procedure. Their doing this for themselves is analogous to a Hollywood actor having an Oscar made for himself and then openly presenting it to himself. The fact that not a murmur was heard from management about this unusual but well known stretching of the boundaries indicates that the collateral organization's restructuring of the boundaries of the larger organization had been successful. This is another excellent example of the collateral organization's creation of a shared reality followed by its successful promotion of that orientation in the larger organization.

The playfulness as boundary stretching was most evident when siddoway proclaimed the corporate CEO as having "gone ballistics." If the group had not indulged in any other playful, irreverent, cocky, or self-congratulatory communication besides the ballistics remark, this statement alone would have 
assured Siddoway and his group a place in the legends of the corporate culture.

Zand (1981) predicts that the norms of the collateral organization would carry over into the larger organization (p. 67). This seems to have happened at Defcon. The norms carry over partly because members from disparate parts of the large organization have a close relationship with each other as a result of working on the collateral organization together. This in turn affects their communication within their own areas. Also, because the collateral organization has affected the proposal process throughout the entire company, and because many of their playful rituals have become staples in the folklore at Defcon, there seems to be a correlation between outrageous goings-on and success in some peoples' minds.

9. The metaphoric lanquage stemming from the celebratory communication of the collateral organization was probably an impetus for risk-taking and further innovation. The irreverent and playful properties of this new communication mode were not the only characteristics evidenced at the meetings. The impatient aspect to their work remained intact. Mr. Siddoway continually 
told his "team" that they needed to "move on it pronio."

This bandit metaphor was also revealed in the newfound opportunistic nature of the collateral organization. Far from being tentative in these later stages, the collateral organization in its bandit phase was quick to leap upon any "opportunity," however small.

For instance, at this time the head corporate office of Defcon, located on the east coast, began a push to regularize methodologies for all sectors in the corporation. To this end, the corporate office decided to set up a new proposal methodology. The head of Defcon Engineering on the west coast (RT) decided to use siddoway as the west coast representative on the corporate collateral organization. By this time, siddoway's "move on it pronto" approach had resulted in the automated proposal methodology that he had been seeking from the automated decision making system. In fact, the automated methodology was simply a detailed version of the tool, specifically applied to proposals. The new innovation and siddoway's new status on a corporation-wide team were the subject of conversation at the regularly scheduled meeting held on september 27,1988 : 
TC: We are sooo lucky! Here's De Lima [corporate CEO] and God [west coast CEO] both hot for an automated proposal methodology just when the c.o.'s doing it!

WS: Join the real world, $\mathrm{m}^{\prime}$ man. Last month when I made that presentation back east I heard a rumor floating around that this was in the works. So, I knew we could get it together in time. After all, God's wish is my command. CZ: How come you didn't tell us that?

WS: So if the enemy captured and tortured you, it would not be revealed!

CZ: Very funny. How come?

WS: Because I wasn't really sure we could make it on time. I didn't want the rumor mill to get ahold of any of this, either.

DD: I've got a question. Are we done? Haven't we made the proposal process a hundred percent better?

WS: What do you think, clarkson?

TC: I think we need a new centralized marketing operation. (Laughter)

WS: I think we have lots of things we can do. And if we don't do them while we've got the drawer to the cash register open, we're never going 
to have another crack at it.

TB: What happens if or when we get shut down again?

WS: We'll bump 'em off. (Laughter)

TB: We will?

WS: No, actually have a contract taken out on the whole bunch.

The nickname "God" that Clarkson used on the Defcon CEO was explained as being apt, because "like God, you're pretty sure he's listening, but he never responds." This communication by this time was almost a new language that the group members adopted unconsciously in each others' presence. The nicknames, the irreverent dig at management, the reference to past failures, were all a continuation of this selfcongratulatory type of communication begun immediately after the first success. The need for speed remained, and a new property was now added to this phase: the references to the "team," "torture," and "bumping them off," added an element of skirting danger. In fact, this was appropriate because of some of the bandit-like manipulations of their leader. But the whole group fell into this intimate sharing of adventure with gusto.

Mr. Siddoway's specific strategies for opportunistic innovations were constantly reiterated: 
"we've got our hand in the cash register; we've got to keep it open," and "we've got to keep our foot in the door before they slam it shut," were repeated at every meeting.

An analogy to this phase of the collateral organization can be found in the medical literature. A human being can succumb to an infection that is not fatal when it moves quickly in the wake of an original infection. The stage is set for this opportunistic infection when the body is "altered or breached" by the first organism. Exactly in the manner of opportunistic infections, opportunistic innovations pushed behind the accepted innovation as it was being implemented. siddoway stated the philosophy very succinctly in his admonitions to "keep our foot in the door before it gets slammed shut," and "keep our hand in the cash register."

The opportunistic innovations were effectively pushed through at breakneck speed after the proposal specialists were accepted. There were no pauses and no attempts were made by management to contain this barrage of innovations.

The philosophy underlying the pushing through of opportunistic innovations is the exact opposite of all budget requests and engineering projects themselves. 
On budget requests, the manager traditionally asks for much more than he both needs or is expecting. on engineering projects, the engineer starts at the top level and decomposes the job into increasingly smaller pieces, which are derived by segmenting the nigher level job.

Siddoway realized when the proposal specialists idea was approved, that part of its appeal lay in how "small" an idea it was. It required the hiring of some new people. This was a very minute budgetary request in this organization. Defcon had spent a great deal of prior time and effort attempting to solve its proposal failures, rendering the request to hire a few new people as essentially an irresistible idea.

Although this went against all of siddoway's former training, and his former method of "asking for more than you want," he made this concept of smaller is better the underlying philosophy of the successful phase of innovations.

The subsequent collateral organization meetings took place with several communicative elements firmly in place: 1) siddoway was the leader and initiated the innovation processes; 2) siddoway trusted the collateral organization with his secrets; 3 ) the collateral organization felt they should "go for 
broke." This phrase ("go for broke") took over as the main slogan of the collateral organization. Siddoway had first abstracted the thought that the foot in the door was impetus to push the door wide open. This philosophy provided an urgency to all their decisions and innovations. One of the most humorous moments at a meeting occurred when clarkson imitated Siddoway's distinctive east coast accent and admonished the group: "Go for broke pronto and keep your hand in the cash register."

The communicative properties that had been emerging throughout this very successful phase for the collateral organization, solidified into a strongly upbeat, cocky, irreverent, optimistic, powerful, and urgent type of communication. Their communication abounded with "in" jokes that poked fun at most of the formal communication in the organization. In other words, the collateral organization defined a reality for themselves and reflected it in their language. The reality that the collateral organization had created was structured around their seeing themselves as reckless bandits. This, however, is not as farfetched as it might seem, nor is the disparity from their original uncertain identity so striking. Joseph Conrad tells us in Lord Jim that the line between a 
coward and a hero is a very fine one; they are one or the other based on a split second's worth of reflection. So it is with the recklessness of the collateral organization. For, as Alchian (1950) states: "Those who are different and successful 'become' innovators, while those who fail 'become' reckless violators of tried-and-true rules" (p. 218). 
CHAPTER IV

LET A HUNDRED FLOWERS BLOOM:

IMPLICATIONS FOR INNOVATION RESEARCH

Many visitors to foreign cultures find the textbook

language they studied in school woefully inadequate for

actually communicating in the new culture. The

communication patterns in the "real world" of the new

culture are not predicted in the textbooks.

Similarly, in this study, previous research on

diffusion of innovations was used as a starting point

for actual field work in the study of innovation

communication. In the process, this author, like the

languageless tourist, was unable to find in the field

the same communication taking place as that described

in the organizational communication literature.

This is not to say that the literature does not speak clearly and convincingly, but simply that it speaks another dialect. Specifically, innovation researchers such as Rogers are modelling innovation diffusion through a network of often loosely related individuals, whereas this study undertook to examine intra-group innovation communication. Thus, it is not surprising that a model explicating the diffusion network would not fit intra-group communication. For instance, many authors define various stages in 
the process of innovation diffusion in organizations. Rogers and Agarwala-Rogers (1976) identify initiation and implementation stages in the process (p. 156). Kanter (1988) offers a more detailed model of the process, with idea generation, coalition building, idea realization, and transfer as her four stages (p. 173).

In the intra-group setting studied here, coalition building is anticipated and in fact mandatory during the period of idea generation. Thus, while from a network perspective it is accurate to distinguish between these two separate activities, in terms of actual intra-group communication, the two activities merge together. That is, idea generation and coalition building are two types of action, but not necessarily two separate and distinct phases. They may be named as two separate phases, but those names may hide as much as they reveal, since the innovation communication in each is indistinguishable from that in the other. The group generates an innovative idea, and looks ahead to effective ways to sell that idea, all in one seamless communicative flow.

Furthermore, Kanter's term "coalition building" suggests a political metaphor of disparate parties banding together to achieve a common end. However, the data in this study suggest that some minimal critical 
mass was not needed to "outvote" the other side. Instead, in this case at least, a communication model fits better than a political one. Specifically, the innovators had to accurately assess the decision makers, learn to anticipate the conceptual world of key decision makers, and recognize ahead of time where and when to stop. Failure to pre-assess the audience's likely stance resulted in the rejection of the centralized marketing idea. The innovators did not need a better coalition; they needed a smaller idea--one that fit their situation and their audience more accurately. In a word, they needed an idea they could communicate better. This study was not designed to do network analysis to see exactly which organizational channels were used, but rather to assess the communication taking place in the collateral organization. That communication did not correspond to the particular phase boundaries elaborated on in the diffusion of innovation network analyses.

These data do not seem to fit into any such neat categories as the phase boundaries suggest. Bits and pieces of the data could be construed as supporting one such set of stages, but other bits and pieces would seem to support other models. Furthermore, much of the data does not readily fit into any particular set of 
innovative stages. For instance, at Defcon, persuasion and implementation seemed to be occurring simultaneously. This was most clearly seen in the "small idea" phenomenon, in which the small idea was implemented specifically as a strategy for convincing the decision makers to accept the larger idea. Hence, the small idea merges implementation and persuasion in one event.

In a similar vein, the data in this study do not support one set period of coalition building. A network analysis, which is outside the scope of this study, may reveal that coalition building was part of the larger picture. For instance, the coalition between the east and west coasts, which brought about the acceptance of the proposal methodology, took place not in the early stages of the idea, but late in the game, and very much unplanned and opportunistically. Thus, the data in this study at least do not support the existence of a separate and early stage of the innovation process during which coalitions were formed. The language of the innovation communication data in this study is simply not the language of the diffusion of innovation network stages that is found in the literature.

The difference is not just between network analysis 
and innovation communication analysis. This gap is also one between the laboratory and the field. This gap between the language of the literature and the language of the field applies to many aspects of innovation research. The general principle is identified by Kimberly (1981), who states, "There is often a considerable gap between the rhetoric and the reality of managerial innovation" (p. 99). Peters and Waterman (1982) also make this point, emphasizing that in presenting vignettes of real organizational interaction, theorists often overlook much conventional wisdom based on actual experience in the field ( $p$. 102). Goodall (1984) concurs that the gap between "real" organizational life, and what one reads and learns as "ideal," are exceptionally disparate. In the process, he says that we "seem to be educating students not to be concerned with knowledge, interpretations, or feelings about working and communicating at work, but instead inducing them to use the partial language of our restricted codes. . ." (p. 136).

The cumbersome aspects to gathering data from so many sources over time were more than made up for by the opportunity to verify, typify, and discard ideas based on realistic contexts and points of view. For example, all of the innovation scholars stress the 
importance of a high volume of open communication as essential for innovation. Specifically, Aiken and Hage (1971) stress the importance of scheduled and unscheduled communications in the context of various hierarchies of groups within the larger organization. Their claim is that both types should occur in a "high intensity" in order for innovation to take place (p. 79). Thus, this author was predisposed to look for such communication taking place in such contexts; however, none was evident.

Another example of the literature failing to agree with what this author found in the field is the strategy advocated by Rowe and Boise (1974) that a rational climate and process must be maintained throughout the innovation process, especially in the implementation stage. Rowe and Boise use terms such as "sufficiently orderly" and "guided by system criteria" to characterize this rational climate (p. 288). Furthermore, they make it clear that they are talking about both the internal and external climates within which the innovation must be spread: "Externally, a climate which tends to be associated with organizational innovation is similar to the internal climate which promotes innovative behavior" (p. 288). In terms of this study, these two similar climates 
include both conditions in the larger organizational world outside the collateral organization and conditions which the collateral organization tried to create within itself and then export.

For example, they state that "the need for highly rationalized and orderly processes during the implementation of an innovation is even more apparent" (p. 288). This call for rationality seemed to fit the initial activities of the Defcon collateral organization. However, events in the larger organizational world forced the collateral organization out of the smooth five-part pattern described by Rowe and Boise (p. 289). Specifically, as soon as the diffusion pattern changed (after the initial rejection), the innovation communication changed also. At this point then, the five-part diffusion model was no longer followed. After the rejection of the first innovation, the communication based on pure inference and argument stopped, and was replaced by the affective and the "bandit" communication. This communication was not irrational, and it was still persuasive. But it was accomplished using different means of persuasion than before. It made use of a wider range of persuasive devices than just inference. It was less orderly and guided by system criteria, but it still effectively 
persuaded, by using more devices than merely the inferences that were formerly the exclusive approach.

Thus, it appears that the communication this author identified at Defcon is to some extent context specific. That is, the innovation communication at Defcon was more influenced by the situation there than it conformed to the predictions of the communication literature. As predicted by Pacanowsky and O'Donnel1-Trujillo (1983), the words this author heard throughout her six-month residence at Defcon "had meaning only in some context" (p. 132). The communication "belonged to the situation," but these features did not determine the meaning, so much as mutually elaborate on each other. In this mutual elaboration of theory and reality are the ultimate implications of this study and the fruitful paths for further research along these lines.

\section{Opportunistic Innovations}

The notion of seeding innovations with a small start and building to a larger innovation is a major implication of this study, which also bears more study, because this is not the current textbook approach to innovation communication research. The current view of innovation scholars is best illustrated by Rogers 
(1983), who states that the level of knowledge about an innovation is positively correlated with its likelihood of adoption (p. 235). But in this study, a high level of knowledge about an innovation did not always correlate with its acceptance. For instance, when Siddoway and Clarkson attempted to prepare Mr. Johnson by revealing the nature of the centralized marketing innovation, they were quickly rejected before they had a chance to explain their reasons. Thus, at Defcon at least, the plan of starting small and building up to a large innovation was often the best and sometimes the only path open.

The notion of opportunistic innovations is thus an instance of a phenomemon that this author found in the field but not in the literature. For instance, Zaltman, Duncan, and Holbek (1973) comment that there is a positive correlation between cost and acceptance of an innovation (p. 33). That is, the more expensive the innovation is, the more likely it is to be accepted. The reasoning is commonly called "snob appeal"; if it is expensive, it must be good. However, Daft and Becker (1978) state that there is no correlation between cost and acceptance or rejection of an innovation (p. 46). This would imply that, in terms of cost at least, a small idea would be accepted no 
more easily than a large one. Finally, zaltman, Duncan, and Holbek (1973) do discuss briefly the idea of a trial implementation (p. 67), but this refers to trial over a short period of time, not the implementation of a small scale version of an idea that may be grown later. The "start small" idea that worked for the Defcon collateral organization was thus not the expected approach for the organization to take. In fact, they themselves only took this approach when their initial more straightforward approach was rejected. Further research using other disciplines where the "start small" idea is already established may reveal underlying principles that can be useful in innovation research as well.

Kelley (1976) suggests that an innovation may be easier to introduce if its newness is played down. However, this idea concerns a strategy for presenting the innovation itself, not an interactive opportunistic context in which the innovation may most effectively be presented.

At Defcon, the smaller (and cheaper) prototype data base was accepted first and was a necessary precursor to the larger, full scale (and expensive) data base. Far from being more acceptable on its own, acceptance of the large data base required the opportunity 
provided by the smaller prototype. Hence, at Defcon opportunistic innovations were actually simply a specific instance of the starting small hypothesis. Further research at other locations besides Defcon could reveal if the situation there is typical (with the small starts providing an opportunity for larger innovations) or if the literature more closely exemplifies the situation at most locations.

\section{Selective Disclosure}

Another major implication of this study is that the open communication stressed by innovation researchers as essential to successful innovation did not take place at Defcon, yet many innovations were successfully introduced. One researcher who recognizes the proliferation of non-open communication is Eisenberg (1984), who under the label of "strategic ambiguity" has argued that such clarity is not necessarily positive: "the overemphasis on clarity and openness in organizational teaching and research is both non-normative and not a sensible standard against which to gauge communicative competence or effectiveness" ( $p$. 228). As Eisenberg points out, such a view is in harmony with modern interactive views of reality, such as the phenomenological view on which this study is 
based (pp. 228-229).

However, Eisenberg's notion of strategic ambiguity is not the same as the selective disclosure the author identified at Defcon. The difference lies in the motivation of the communicator and the point of view from which the researcher is looking. Strategic ambiguity comes from an epistemological point of view and focuses on the message itself. Selective disclosure comes from the psychological point of view, and examines the communicator's motivations, which underly the particular choices the individual makes in withholding certain parts of the message. The phenomenon of selective disclosure observed at Defcon is an exercise in power and politics on the part of would-be "bandit" innovators striving to get their ideas accepted in the larger and more formal organization. Selective disclosure is a way of manipulating their messages and their audiences for maximum innovative effect. It is a quality of the communicator reflected in the communication, not a quality of the communication as a disembodied piece of discourse in the network context. In other words, selective disclosure is an attempt to account for and rationalize the motivations for a certain type of communication chosen by many innovators at Defcon. 
More research needs to be done in other organizations to see if the effort toward innovation regularly leads to selective disclosure and if selective disclosure can be observed in any other contexts other than innovative ones.

Formal vs. Informal structures Most of the literature dealing with formal and informal communication stresses their interrelated nature, making the two seem like parallel channels for the same message. For instance, using a chronological process model, Martilla (1971) found that formal communication channels are important in the early stages of the innovation process, but informal channels are more important later in the process, when the decision is made to actually adopt the innovation. Thus, formal and informal communication each has its own time and place in a single innovation process. However, Schwartzman (1981) presents a more integrated relationship between formal and informal communication. Perhaps this is because she takes a more integrative perspective combining message and channel in one point of view. Studying work and play at a mental health center, she comments that "work is clearly not separate from play, and research that 
perpetuates this distinction will continue to produce distorted characterizations of organizing and the everyday life of organizational members" (p. 87). Significantly, schwartzman, in taking a more broadly intra-group, communication-centered approach than the diffusion scholars, implicitly notes the same distinction between the language of the literature and the language of the field that this author has noted as well.

This author's work at Defcon strongly supports both the interrelationship of formal and informal communication as well as the centrality of playful communication and its close interrelationship with the more studied formal channels of "normal" organizational communication. However, the data in this study are not conclusive on this point, as they are from an intragroup perspective, not a network analysis.

Nonetheless, this research seems to indicate that the formal and informal channels are much more interrelated and much less separate and distinct than current textbooks suggest. For instance, Downs (1967) distinguishes between formal and subformal communications, equating the two rigidly with "official" bureaucratic channels and "purely informal" channels (p. 113). Downs does briefly mention the 
possibility of non-formal communication occurring in formal channels, but the idea is not elaborated on. However, the data in this study imply that in the innovation process the merging of formal and informal communication may be important to the success of the innovative proposal. Specifically, it may be possible, as Schwartzman suggests, to "dance" at a formal meeting. In fact, as in the "went ballistics" comment, this sudden intrusion of an informal communication in the most formal setting seemed to happen with regularity at Defcon, and was often instrumental in the proposed innovation being accepted.

More research needs to be done, especially with the informal channels and the playful communication to see if and how they overlap with each other, and even more importantly, how they each relate to the formal channels as well.

\section{Shared Reality}

Finally, it seems evident from this study that members of various organizations do build a shared reality, as is implied in the phenomenological view of organizations. This idea is not unusual in the literature. For instance, Weick (1979) uses the term "enacted environment" to suggest a reality that 
organizational members construct (pp. 164-165). But in Weick's book, as in all the literature this author examined, the notion of shared reality was not applied to innovation communication. For instance, Bormann (1983) mentions many examples of shared reality in his work on fantasies, but none is presented in an innovative context, nor is any substantiated with a rich variety of field-generated data. Further research is called for to document and analyze the shared realities through which innovators and innovative organizations (like the collateral organization) create and present their innovations.

The Future of Innovation Research

Rosabeth Moss Kanter (1988) of Harvard University concludes her article "When a Thousand Flowers Bloom" with the assertion that "making a thousand flowers bloom is not a fully random or accidental process, unless we are satisfied with spindly, fragile, wildflowers. Instead, the flowers of innovation can be cultivated and encouraged to multiply in the gardens of organizations designed on the integrative model, organizations where the growth rhythm of innovation is well understood" (p. 205).

This author fully concurs that innovation can best 
flourish where the "growth rhythm" is well understood. This study was an attempt to add some understanding to the seemingly disordered and serendipitous process by which the flowers of innovation grow. However, Kanter seems to miss the irony of the title of her article, which is a paraphrase of the "Hundred Flowers" statement by Mao zedong, inviting criticism of the Chinese Communist government. Critics did come forth, but after only a short time, the government decided it had had too much criticism and arrested everyone who had made any suggestions, putting most in jail for periods up to several years. It seems that in the case of the Hundred Flowers movement at least, innovation was not really wanted. The ultimate conclusion to the aborted Hundred Flowers movement was the Cultural Revolution, one of the least innovative periods in world history.

Innovation, and would-be innovation, can certainly go awry. The hundred flowers can wither and die very quickly, and even trying to grow them can become dangerous and counterproductive. This is most likely to occur at times where the nature of the innovation is not adequately understood or fully accepted by those in charge, or when the nature of the decision makers is not adequately understood by those making the 
innovative suggestions. Both of these were the case in the Hundred Flowers movement in China and are all too often the case with innovative movements elsewhere. The major insights from this study each relate to one or more dangers to the innovation process.

First of all, innovation can wither if it is brought forth without an accurate understanding of the environment in which it is proposed. The few Chinese citizens who didn't understand the reality of authoritarian rule quickly found themselves in prison or dead as the price for their unfamiliarity with the real world. In innovation communication more than in many other kinds of communication, the distance between the textbook version and the actual version spoken on the street is very great. As Kimberly (1981) suggests, "As a matter of course, innovation advocates would do well to test the climate for innovation carefully before initiating a project" (p. 93). This goes for researchers as well. For scholars and for organizations, where they are and how their effort fits into the larger picture must be established first of al1. The flowers of innovation do not grow on isolated islands.

Second, innovation can be harmful if it is brought on too quickly. Paradoxically, unless the environment 
is extraordinarily favorable, a small idea actually has considerably more power and longevity than a large one. For the careful innovator, the idea is to test the language of innovation with a small piece of discourse before trying the full text. If the small piece goes well, it is that much easier to bring along the next idea. Seedlings are developed and then transplanted, not full-grown plants. Just as a non-native speaker experiences an exponential increase in linguistic skills when placed in the right environment, so a small seed idea can quickly grow into a whole and healthy garden of flowers if properly tended.

Third, the innovative organization must develop its own sense of shared reality, which it can use as an export device or innovative medium to the larger organization. As Putnam (1982) puts it, "The constructed reality, then, is actively maintained through the communicative experiences and the meanings enacted from these behaviors" (p. 200). This idea has not been applied with full emphasis to innovation studies because they have usually taken a diffusion or network point of view, rather than an intra-group, communicative perspective. But the interpretive viewpoint central to this study implies a communicative focus for the study of innovation in organizations: 
"created realities demonstrate and sustain order through communicative experiences. Symbolic processes are vehicles for maintaining the necessary and inevitable order of organizational realities" (Putnam, 1982 , p. 202). The innovative organization nurtures itself in private and gathers strength with which to enter the outside world. The innovation communication at this stage may at first take the form of a private language, understood only in the friendly confines of a hidden corner of the garden. But if that language is cultivated, it will eventually be exportable to other parts of the garden, both as innovations and as better scholarly insight into the intra-group workings of the innovation process itself. 
REFERENCES

Abrahams, R. D. (1977). Toward an enactment theory of folklore. In $W$. R. Bascom (Ed.). Frontiers of folklore (pp. 85-103). Boulder, co: Westview Press.

Aiken, M. \& Hage, J. (1971). The organic organization and innovation. Sociology, $\underline{5}, 63-82$.

Albrecht, T. L. \& Ropp, V. A. (1982). The study of network structuring in organizations through the use of method triangulation. Western Journal of Speech Communication, $46,162-178$.

Alchian, A. (1950). Uncertainty, evolution, and economic theory. Journal of political Economy, 58, 211-221.

Bales, R. F. (1950) - Interaction process analysis. Reading, MA: Addison-Wesley.

Bitzer, L. (1970). The rhetorical situation. Philosophy and Rhetoric, 1, 1-14.

Bogdan, R. \& Taylor, S. J. (1975). Introduction to qualitative research methods. New York: John wiley \& Sons.

Bogdan, R. \& Taylor, S. J. (1984). Introduction to qualitative research methods (2nd ed.). New York: John Wiley \& Sons.

Bormann, E. G. (1983). Symbolic convergence: Organizational communication and culture. In $L$. $L$. Putnam \& M. E. Pacanowsky (Eds.). Communication and organizations: An interpretive approach (pp. 99-122), Beverly Hills, Sage Publications.

Buttny, R. (198.5). Accounts as a reconstruction of an event's context. Communication Monographs, $\underline{52}$, 57-77.

Buttny, R. (1987) . Legitimation techniques for intermarriage: Accounts of motives for intermarriage from U.S. servicemen and Philippine women. Communication Quarterly, 35, 125-143. 
Campbell, J. P., Daft R. L., \& Hulin, C. L. (1982). What to study: Generating and developing research questions. Beverly Hills: Sage Publications.

Carnall, C.A. (1986). Toward a theory for the evaluation of organizational change. Human Relations, 39, 745-766.

Cheney, G., Block, B. L., \& Gordon, B. S. (1986). Perceptions of innovativeness and communication about innovations: A study of three types of service organizations. Communication quarterly, 34, 213-230.

Child, J. \& Smith, C. (1987). The context and process of organizational transformation--Cadbury limited and its sector. Journal of Management Studies, 24, 565-575.

Collins, J. (1988, November 20). It's not creativity we lack but receptivity. San Jose Mercury News, sect. PC, pp. 1-2.

Christians, I. (1985). The deafening silence that conceals fear of change. International Management, $40,68-85$.

Connor, P. E. \& Lake, L. K. (1988). Managing organizational change. New York: Praeger Publishers.

Daft, R. L. \& Becker, S. W. (1978). The innovative organization. New York: Elsevier.

Davis, S. M. \& Lawrence, P. R. (1977). Matrix. Reading, MA: Addison-Wesley Publishing Co.

Deetz, S. A. (1982). Critical interpretative research in organizational communication. Western Journal of Speech Communication, 46, 131-149.

Denzin, N. K. (1978). The research act: A theoretical introduction to sociological methods ( 2 nd ed.). New York: McGraw-Hill.

Downs, A. (1967). Inside bureaucracy. Boston: Little, Brown and Company. 
Dubin, R. (1976). Theory building in applied areas. In M. D. Dunnette (Ed.). Handbook of industrial and organizational psychology (pp. 17-39). Chicago: Rand McNally College Publishing Company.

Eisenberg, E. M. (1984). Ambiguity as strategy in organizational communication. Communication Monographs, 51, 227-242.

Etzioni, A. (1975). Complex organizations. New York: The Free Press.

Farace, R. V., Monge, P. R., \& Russe11, H. M. (1977). Communicating and organizing. Reading, MA: AddisonWesley Publishing.

Faules, D. (1982). The use of multi-methods in the organizational setting. Western Journal of Speech Communication, 46, 150-161.

Fisher, D. (1981). Communication in organizations. New York: West Publishing.

Fisher, B. A. \& Hawes, L. C. (1971). An interact system model: Generating a grounded theory of small groups. Quarterly Journal of Speech, 4, 444-453.

Freedman, G. (1988). The pursuit of innovation. New York: American Management Association.

French, W. L. \& Bell, C. H. (1984). Organization development. (3rd ed.). Englewood Cliffs, New Jersey: Prentice-Hall.

Geist, P. \& Chandler, T. (1984). Account analysis of influence in group decision-making. Communication Monographs, 51, 67-78.

Glaser, B. G. \& Strauss, A. L. (1967). The discovery of grounded theory. Chicago: Aldine.

Goldhaber, G. M. (1986). Organizational communication (4th ed.). Dubuque, Iowa: William C. Brown.

Goodall, H. L., Jr. (1984). Contexts: One rhetorician's lament after a year-long odyssey. Communication quarterly, 32, 133-147. 
Goodman, R. A. \& Goodman, L. P. (1976). Some management issues in temporary systems: A study of professional development and manpower--theater case. Administrative Science Quarterly, 21, 494-501.

Gouran, D. S. (1986). Inferential errors, interaction, and group decision-making. In R. $Y$. Hirokawa \& M. S. Poole (Eds.). Communication and group decision making (pp. 93-111). Beverly Hills: Sage Publications.

Harré, R. \& Secord, P. F. (1973). The explanation of social behaviour. Totowa, New Jersey: Littlefield, Adams.

Harris, P. R. (1983). New world, new ways, new management. New York: American Management Association.

Hedberg, B. L. T., Nystrom, P. C., \& starbuck, W. H. (1976). Camping on seesaws: Prescriptions for a self-designing organization. Administrative Science quarterly, 21, 41-65.

Henderson, S. (1981). Reality bargaining: The emergence of consensual validation. Proceedings of the Conference on Interpretive Approaches to Organizational communication. West Lafayette, IN: Department of communication, Purdue University.

Homans. G. C. (1950). The human group. New York: McGraw-Hill.

Husband, R. L. (1985). Toward a grounded theory of organizational leadership behavior. Quarterly Journal of Speech, 71, 103-118.

Janis, I. L. (1972). Victims of groupthink. Boston: Houghton Mifflin.

Jones, W. M. (1964). On decisionmaking in large organizations. Santa Monica, CA: The Rand Corporation.

Kanter, R. M. (1982). The middle manager as innovator. Harvard Business Review, 60, 95-105. 
Kanter, R. M. (1988). When a thousand flowers bloom: structural, collective, and social conditions for innovation in organizations. Research in organizational Behavior, 10, 169-211.

Katz, D. \& Kahn, R. L. (1978). The social psychology of organizations. (2nd ed.). New York: John Wiley and sons.

Kelley, G. (1976). Seducing the elites: The politics of decision making and innovation in organizational networks. Academy of Management Review, 1, 66-74.

Kelly, P. \& Kranzberg, M. (Eds.). (1978). Technical innovation: A critical review of current knowledge. San Francisco: The San Francisco Press.

Kimberly, J. R. (1981). Managerial innovation. In P. C. Nystrom \& W. H. Starbuck (Eds.). Handbook of organizational design (pp. 84-104). New York: oxford University Press

Labov, w. \& Fanshel, D. (1977) . Therapeutic discourse: Psychotherapy as conversation. New York: Academic Press.

Landen, D. L. \& Carlson, H. C. (1982). Strategies for diffusing, evolving, and institutionalizing quality of work life at General Motors. In Zager, R. \& Rosow, M. P. (Eds.). The innovative organization (pp. 291-335). New York: Pergamon Press.

McLaughlin, M. L., Cody, M. J., \& Rosenstein, N. E. (1983) Account sequences in conversation between strangers. Communication Monographs, 50, 102-125.

March, J. G. (1981). Footnotes to organizational change. Administrative Science Quarterly, 26, 562-572.

Margulies, N. \& Wallace, J. (1973). Organizational change: Techniques and applications. Glenview, IL: scott, Foresman \& co.

Martilla, J.A. (1971). Word-of-mouth communication in the adoption process. Journal of Marketing Research, $\underline{8}, 173-178$. 
Mills, P. K. \& Margulies, N. (1980). Toward a core typology of service organizations. Academy of Management Review, $\underline{5}$, 255-265.

Mouzelis, N. P. (1967). Organization and bureaucracy: An analysis of modern theories. Chicago: Aldine.

Mowday, R. T. \& Steers, R. M. (Eds.). (1979). Research in organizations: Issues and controversies. Santa Monica, CA: Goodyear Publishing Co.

Naisbett, J. \& Aburdene, P. (1985). Re-inventing the corporation. New York: Warner Books.

Nurick, A. J. (1985). Participation in organizational change: The TVA experiment. New york: Praeger Publishers.

Pacanowsky, M. E. \& O'Donnell-Trujillo, N. (1982). Communication and organizational cultures. Western Journal of Speech Communication, 46, 115-130.

Pacanowsky, M. E. \& O'Donnell-Trujillo, N. (1983). organizational communication as cultural performance. Communication Monographs, 50, 126-147.

Patton, M. Q. (1987). How to use qualitative methods in evaluation. Beverly Hilis: Sage Publications.

Peters, T. J. \& Waterman, R. H. (1982). In search of excellence. New York: Harper \& Row.

Pettigrew, A. M. (1987). Context in action in the transformation of the firm. Journal of Management Studies, 24, 649-670.

Putnam, L. L. (1983). The interpretive perspective: An alternative to functionalism. In $\mathrm{L}$. L. Putnam \& $\mathrm{M}$. E. Pacanowsky (Eds.). Communication and organizations: An interpretive approach (pp. 31-54). Beverly Hills: Sage Publications.

Putnam. L. L. (1982). Paradigms for organizational communication research: An overview and synthesis. Western Journal of Speech Communication, 46, 192-206. 
Redding, w. C. (1970). Research setting: Field studies. In F. Emmert \& W. D. Brooks (Eds.). Methods of research in communication (pp. 105-159). Boston: Houghton-Miffin Co.

Rogers, E. M. (1983). Diffusion of innovations (3rd ed.). New York: The Free Press.

Rogers, E. M. \& Agarwala-Rogers, R. (1976). Communication in organizations. New York: The Free Press.

Rowe, L. A. \& Boise, W. B. (1974). Organizational innovation: Current research and evolving concepts. Public Administration Review, 34, 284-293.

Roy, D. F. (1960). 'Banana time': Job satisfaction and informal interaction. Human organization, 18, 158-168.

Sanders, P. (1982). Phenomenology: A new way of viewing organizational research. Academy of Management Journal, 7, 353-360.

Scharf, A. (1987). Improving your personal effectiveness as a change agent. Industrial Management, 29, 15-28.

Schwartzman, H. B. (1981). Hidden agendas and formal organizations or how to dance at a meeting. Social Analysis, 9 , 76-88.

Schwartzman, H. B. (1986). The meeting as a neglected social form in organizational studies. Research in organizational Behavior, $8,223-258$.

Selznick, P. (1948). Foundations of the theory of organization. American Sociological Review, 13, 25-35.

Sheperd, C. R. (196:) . Small groups: Some sociological perspectives. Scranton, PA: Chandler.

Stein, B. A. \& Kanter, R. M. (1980). Building the parallel organization: Creating mechanisms for permanent quality of work life. The Journal of Applied Behavioral Science, 16, 371-386. 
Tompkins, P. K. \& Cheney, G. (1983). Account analysis of organizations: Decision making and identification. In L. L. Putnam \&. E. Pacanowsky (Eds.). Communication and organizations: An interpretive approach (pp. 123-146). Beverly Hills: Sage Publications.

Utterback, J. M. (1971). The process of technological innovation within the firm. Academy of Management Journal, 14, 75-88.

Van Maanen, J. (1983) . Qualitative methodology (2nd ed.). Beverly Hilis: Sage Publications.

Walton, R. E. (1987). Innovating to compete. San Francisco: Jossey-Bass, Inc.

Weick, K. E. (1979). The social psychology of organizing (2nd ed.). New York: Random House.

Whitfill, J. (1981). Life in the county jail: A look at a loosely coupled system. Proceedings of the Conference on Interpretive Approaches to Organizational Communication. West Lafayette, IN: Department of communication, Purdue University.

Whyte, W. F. (1969). organization behavior: Theory and application. Homewood, IL: Dorsey-Irwin.

Zaltman. G., Duncan, R. \& Holbek, J. (1973). Innovation and organization. New York: John Wiley \& Sons.

Zand, D. E. (1974). Collateral organization: A new change strategy. The Journal of Applied Behavioral Science, 10, 63-89.

Zand, D. E. (1981). Information, organization, and power. New York: HcGraw-Hill Book Co.

Zelditch, M., Jr. (1970). Some methodological problems of field studies. In $N$. K. Denzin (Ed.). Sociological methods (pp. 495-511). Chicago: Aldine Publishing Co. 